\title{
The Dynamics of Climate Agreements
}

\author{
Bård Harstad
}

\author{
CESIFO WORKING PAPER NO. 2962 \\ CATEgORY 10: ENERGY AND ClimATE ECONOMICS \\ FEBRUARY 2010
}

Presented at CESifo Area Conference on Energy \& Climate Economics, October 2009

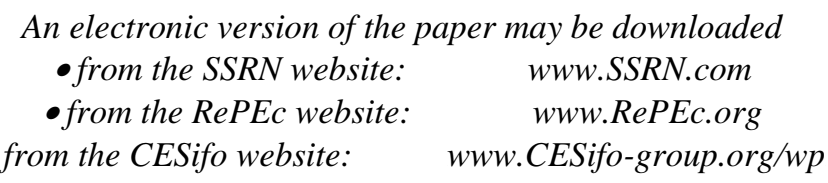




\title{
The Dynamics of Climate Agreements
}

\begin{abstract}
I develop a dynamic model of private provision of public bads allowing investments in technologies. The analysis is tractable and the MPE unique. The framework is used to derive optimal incomplete contracts in a dynamic setting. While the noncooperative equilibrium is very inefficient, short-term contracts can be worse due to hold-up problems. The optimal long-term contract is more ambitious if its length is relatively short and the technological spillover large. The optimal length increases in this externality. With renegotiation, the outcome is first best. The results have several implications for how to design a climate treaty.

JEL-Code: D86, Q54, F55, F53, H87.

Keywords: dynamic private provision of public goods, dynamic common pool problems, dynamic hold-up problems, incomplete contracts, contract-length, renegotiation design, climate change and climate agreements.
\end{abstract}

\author{
Bård Harstad \\ Northwestern University \\ Kellogg School of Management \\ harstad@kellogg.northwestern.edu
}

17 January 2010

I am grateful to the audiences at the 2009 AEA meeting, the University of British Columbia, Caltech, CESifo, the Chicago Area Political Economy conference, the University of Copenhagen, Emory University, the Federal Reserve Bank of Chicago, the FEEM conference on Coalitions for Climate Cooperation, Helsinki School of Economics, the Marshall School of Business, the MSRI conference on climate change, Northwestern University, University of Oslo, Princeton University, Paris School of Economics, Simon Fraser University, Stockholm University, and the World Bank. I have benefitted in particular from the comments of Philippe Aghion, Marco Battaglini, David Besanko, Jeff Campbell, Yeon-Koo Che, Rolf Golombek, Faruk Gul, Michael Hoel, Ben Jones, Larry Karp, Charles Kolstad, Matti Liski, Jiang Ning, Wolfgang Pesendorfer, and Roberto Veneziani. Judith N. Levi assisted with the editing. 


\section{Introduction}

This paper develops a dynamic model of private provision of public goods. The agents can also invest in cost-reducing technologies, leading to $n+1$ stocks, but the analysis is nevertheless tractable. I characterize a unique Markov perfect equilibrium (MPE), compare it to scenarios in which the agents can contract on contributions, and derive the optimal incomplete contract.

The model is general and could fit various contexts. The leading example is climate change, and the results have clear implications for how to design an efficient treaty. Consistent with the model's assumptions, environmental agreements (e.g. the Kyoto Protocol) typically specify emission levels but not investments in technology, since such investments would be hard to verify. They often have a limited time horizon and leave future commitments to be negotiated. ${ }^{1}$ To fix ideas, I thus refer to the agents as "countries", the public bad (i.e., the negative of a public good) as "greenhouse gas" and contributions as "emissions." All countries suffer from the cumulated pollution level, but each country faces a private cost when cutting its own emission. This cost, however, can be reduced by investing in technology (such as abatement technology or renewable energy sources). There might also be technological spillovers when a country makes such investments, since other countries may be able to utilize the knowledge thereby generated.

The real investment cost function may be convex or concave (if there are increasing returns to scale). By assuming it is linear, I analytically derive a unique MPE, even though there is a large number of stocks in the model. This MPE is stationary and coincides with the unique subgame perfect equilibrium if time were finite but approached infinity. Since the MPE is unique, agreements enforced by trigger strategies are not feasible. But in reality, even domestic stakeholders might act as enforcers if the agreement must be ratified by each country. While abstracting from domestic politics, I vary the countries' possibilities or negotiating, contracting and committing, and derive the best agreement for each situation. Since each equilibrium contract is also the constrained optimum, the results can be interpreted normatively.

To begin with, countries act noncooperatively at all stages. If one country happens to pollute a lot, the other countries are, in the future, induced to pollute less since the problem is then more severe. They will also invest more in technology to be able to afford the necessary cuts in emissions. On the other hand, if a country invests a lot in abatement technology, it can be expected to pollute less in the future. This induces the other countries to increase their emissions and reduce their own investments. Anticipating these effects, each country pollutes more and invests less than it would in an otherwise similar static model. This dynamic common pool problem is thus particularly severe.

Short-term agreements on immediate emission levels can nevertheless be worse. A hold-up problem arises when the countries negotiate emission levels: if one country has better technology and can cut its emissions fairly cheaply, then its opponents may ask it

\footnotetext{
${ }^{1}$ According to the UN, "The major feature of the Kyoto Protocol is that it sets binding targets...for reducing greenhouse gas (GHG) emissions... over the five-year period 2008-2012...By the end of the first commitment period of the Kyoto Protocol in 2012, a new international framework needs to have been negotiated" (http://unfccc.int/kyoto_protocol/items/2830.php). The more recent Copenhagen Accord also requests the specification of emission levels, but not of levels of R\&D.
} 
to bear the lion's share of the burden when collective emissions are reduced. ${ }^{2}$ Anticipating this, countries invest less when negotiations are coming up. This makes everyone worse off, particularly if the length of an agreement is short and the number of countries large.

Long-term agreements may better mitigate the hold-up problem. If commitments are negotiated before a country invests, it cannot be held up by the other countries - at least not before the agreement expires. Thus, countries invest more when the agreement is long-term. Nevertheless, countries under-invest if (i) the agreement does not last forever or (ii) the technological spillover is large. To encourage more investments, the best (and equilibrium) long-term agreement is tougher and stipulates lower emissions compared to the optimum ex post, particularly if the technological spillover is large and the length of the agreement relatively short. Since investments decrease toward the end of the agreement, the agreement should become tougher over time to motivate investments. The optimal length of an agreement increases in the technological spillover, I find.

However, such long-term agreements are not renegotiation-proof. Once the investments are sunk and the state of the world realized, countries have an incentive to negotiate ex-post optimal emission levels rather than sticking to an overambitious long-term agreement. When renegotiation is possible and cannot be prevented, an investing country understands that it does not, in the end, have to comply with overambitious contracts. Nevertheless, with renegotiation, all investments and emissions are first best. Intuitively, emission levels are renegotiated to ex-post optimal levels. Countries with poor technology find it particularly costly to comply with an initial ambitious agreement and will be quite desperate to renegotiate it. This gives them a weak bargaining position and a bad outcome. To avoid this fate, countries invest more in technology, particularly if the initial agreement is very ambitious. Taking advantage of this effect, the agreement should be tougher if its length is short and the technological spillover large, just as in the case without renegotiation.

In reality, the externalities from investments are related to international trade and law. Poor protection of intellectual property rights allow countries to benefit without having to pay. If trade in abatement technology is possible, import tariffs may reduce the exporter's price and increase the externality for free-riders. International subsidies, either on investments or trade in abatement technologies, do the opposite. Thus, with small subsidies, high tariffs and poor protection of intellectual property rights, the externality is larger and countries under-invest. In these circumstances, the results suggest that the climate treaty should be tough and long-lasting. Vice versa, if the countries can only commit to short-lasting and weak climate treaties, investment subsidies, tariff reductions and intellectual property rights become more important. This way, the externality is endogenized.

The next section clarifies the paper's contribution to the literature on dynamic games, incomplete contracts, and environmental agreements. The model is presented in Section 3. When solving the model in Section 4, I gradually increase the possibilities for negotiations and contracts: (i) no cooperation, (ii) short-term agreements, (iii) long-term

\footnotetext{
${ }^{2}$ Financial Times reports that "Leaders of countries that want concessions say that nations like Denmark have a built-in advantage because they already depend more heavily on renewable energy" (October 17, 2008, p. A4). Although the Kyoto Protocol aimed for uniform cuts relative to the 1990 levels, exceptions were widespread and there is currently no attempt to harmonize cuts.
} 
agreements, and (iv) long-term agreements with renegotiation. I start out by assuming that investments are noncontractible, technologies nontradable, quotas nontradable, firms nonexistent, and countries homogeneous. All these assumptions are relaxed in Sections 5 and 6. Section 7 concludes, while the Appendix contains all proofs.

\section{Contributions to the Literature}

By developing a (i) dynamic (difference) game permitting (ii) incomplete contracts interpreted as (iii) environmental agreements, the paper contributes to three strands of literature.

\subsection{Dynamic games}

Private provision of public goods is often studied in differential games (or a difference game, if time is discrete) where each player's action influences the future stock or state parameter. ${ }^{3}$ Given the emphasis on stocks, the natural equilibrium concept is Markov perfect equilibrium. As in this paper, the typical conclusion is that public bads (goods) are over-provided (under-provided). ${ }^{4}$

Differential games are, however, often difficult to analyze. This has several implications: First, many authors restrict attention to linear-quadratic functional forms (Engwerda, 2005). Second, while some papers arbitrarily select the linear MPE (e.g., Fershtman and Nitzan, 1991), multiple equilibria typically exist (Wirl, 1996; Tutsui and Mino, 1990). Consequently, many scholars, like Dutta and Radner (2009), manage to construct more efficient nonlinear MPEs. ${ }^{5}$ Third, few bother complicating their model further by adding investments in technologies. One exception is Dutta and Radner (2004), who do add explicit investments in technology. But since the cost of pollution (as well as the cost of $R \& D$ ) is assumed to be linear, the equilibrium is "bang-bang" where countries invest either zero or maximally in the first period, and never thereafter.

The first contribution of this paper is to develop a tractable model, with a unique MPE, that can be used to analyze investments as well as emissions. This is achieved by assuming that technology has a linear cost and an additive impact. This trick simplifies the model tremendously, and it may also be used when studying unrelated topics. In the literature on industry dynamics, for example, analytical solutions are rare and numerical simulations necessary. ${ }^{6}$

\footnotetext{
${ }^{3}$ For overviews, see Başar and Olsder (1999) or Dockner et al. (2000).

${ }^{4}$ This follows if private provisions are strategic substitutes (as in Fershtman and Nitzan, 1991, and Levhari and Mirman, 1980). If they were complements, e.g. due to a discrete public project, efficiency is more easily obtained (Marx and Matthews, 2000).

${ }^{5}$ See also Dockner and Long (1993), Dockner and Sorger (1996), and Sorger (1998).

${ }^{6}$ See the survey by Doraszelski and Pakes (2007). A firm typically over-invests in capacity to get a competitive advantage. While Reynolds (1987) restricts attention to the linear MPE in a linear-quadratic model, a simple two-stage game is used by d'Aspremont and Jacquemin (1988) to discuss the benefits of cooperation and by Gatsios and Karp (1992) to show that firms may invest more if they anticipate future merger negotiations. When allowing negotiations on price (but not on investments) in a more general
} 
My second contribution, made possible by the first, is to incorporate incomplete contracts in dynamic games. Few papers allow for policies or negotiation in differential games. $^{7}$ In Battaglini and Coate (2007), legislators negotiate spendings on pork and a long-lasting public good. The equilibrium public-good level is suboptimally but strategically low to discourage future coalitions from wasting money on pork. This argument relies on majority rule, however, and the contract incompleteness is related to future policies rather than current investments.

\subsection{Incomplete contracts}

By permitting contracts on emissions but not on investments, this paper is in line with the literature on incomplete contracts (e.g., Hart and Moore, 1988). ${ }^{8}$ I show that investments decrease toward the end of a contract, the best contract becomes tougher over time, and the optimal length increases in the spillover. ${ }^{9}$ The result that short-term agreements can be worse than no agreement at all is certainly at odds with the classical literature that focuses on bilateral trade.

When renegotiation is possible, moral hazard problems are often expected to worsen (Fudenberg and Tirole, 1990). But Chung (1991) and Aghion et al. (1994) have shown how the initial contract can provide incentives by affecting the bargaining position associated with particular investments. While these (and related) models have only one period, Guriev and Kvasov (2005) present a dynamic moral hazard problem emphasizing the termination time. Their contract is renegotiated at every point in time, to keep the remaining time horizon constant. Contribution levels are not negotiated, but contracting on time is quite similar to contracting on quantity, as studied by Edlin and Reichelstein (1996): if the externality increases, Guriev and Kvasov find that the contract length should increase, while Edlin and Reichelstein show that the contracted quantity should increase. In this paper, agents can contract on quantity (emissions) as well as on time, allowing me to study how the two interact. I also allow an arbitrary number of agents, in contrast to the buyer-seller situations in these papers.

setting, Fershtman and Pakes (2000) use numerical analysis.

${ }^{7}$ Hoel (1993) studies a differential game with an emission tax, Yanase (2006) derives the optimal contribution subsidy, Houba et al. (2000) analyze negotiations over (fish) quotas lasting forever, while Sorger (2006) study one-period agreements. Although Ploeg and de Zeeuw (1992) even allow for R\&D, contracts are either absent or complete in all these papers.

${ }^{8}$ In dynamic settings, hold-up problems may be solved if the parties can invest while negotiating and agreements can be made only once (Che and Sakovics, 2004), or if there are multiple equilibria in the continuation game (Evans, 2008). Neither assumption is satisfied in this paper, however.

${ }^{9}$ Very few papers study the optimal length of contracts. Harris and Holmstrom (1987) discuss length when contracts are costly to rewrite, but uncertainty about the future makes it necessary. Ellman (2006) studies the contract "length" (the probability for continuing the contract) and finds that it should last longer if specific investments are important. This is related to my result on the optimal time horizon, but Ellman has only two agents, one investment period, and uncertainty is not revealed over time. 


\subsection{Environmental agreements}

There is a growing literature on climate policy and environmental agreements. ${ }^{10} \mathrm{My}$ main contribution to this literature is to add dynamics and incomplete contracts. This generates several novel results, including my finding that short-term agreements are bad while long-term agreements better mitigate hold-up problems. Karp and Zhao (2009), for example, recommend decade-long short-term agreements, partly to ensure flexibility. The present paper demonstrates, however, that flexibility is better assured by long-term agreements with renegotiation.

Assuming nonverifiable R\&D is quite standard. ${ }^{11}$ Thus, the result that agreements should be ambitious in order to induce R\&D has been observed also in two-stage games (Golombek and Hoel, 2005). But my result that (short-term) agreements can reduce R\&D is at odds with most of the literature, which instead emphasizes the positive impacts of regulation on technological change. ${ }^{12}$ Hoel and de Zeeuw (2009) also find that R\&D can decrease if countries cooperate because they then reduce pollution even without new technology, although there is no negotiation (and their analysis hinges on a "breakthrough technology" and binary abatement levels). That R\&D might decrease prior to negotiations was first noted by Buchholtz and Konrad (1994). More recently, Beccherle and Tirole (2010) generalized my one-period model and showed that anticipating negotiations can have adverse effects also if the countries, instead of investing, sell permits on the forward market, allow banking, or set production standards. With only one period, however, these models miss dynamic effects and thus consequences for agreement design. ${ }^{13}$

\section{The Model}

\subsection{Stocks and Preferences}

This section presents a game where $n$ players over time contribute to a public good and invest in technology. The purpose of the technology is to reduce the cost of providing public goods in the future. While the model is general, let climate change fix ideas. I will thus refer to the players as countries, the public good (or its negative: the public bad) as the stock of greenhouse gases, and to contributions as emissions. ${ }^{14}$

The public bad is represented by the stock $G$ of greenhouse gases in excess of its natural

\footnotetext{
${ }^{10}$ See Kolstad and Toman (2005) on climate policy and Barrett (2005) on environmental agreements. Aldy et al. (2003) and Aldy and Stavins (2007) discuss alternative climate agreement designs.

${ }^{11}$ If trying to contract on R\&D, Golombek and Hoel (2005, p. 202) note that "it will be relatively easy for the country to have less R\&D than required by the agreement, but to report other expenditures as R\&D activities."

${ }^{12}$ See, e.g., Jaffe et al. (2003) or Newell et al. (2006). Even when investments are prior to negotiations, Muuls (2009) finds that they increase investments.

${ }^{13}$ Many dynamic models of climate treaties focus on the number of participants (see, e.g., Barrett and Stavins, 2003; Rubio and Ulph, 2007; and their references). In my model, however, all countries participate in equilibrium since I do not allow them to commit to not negotiating with the others.

${ }^{14}$ Nevertheless, I abstract from heterogeneities within countries and oil exhaustability. The strategic effects studied below would survive if these complications were added to the model.
} 
level. Since the natural level is thus $G=0, G$ tends to approach zero over time (were it not for emissions), and $1-q_{G} \in[0,1]$ measures the fraction of $G$ that "depreciates" every period. $G$ may increase, nevertheless, depending on the emission level $g_{i}$ from country $i \in\{1, \ldots, n\}$ :

$$
G=q_{G} G_{-}+\theta+\sum_{i} g_{i}
$$

$G_{-}$represents the stock of greenhouse gases left from the previous period; subscripts for periods are thus skipped. The shock $\theta$, arbitrarily distributed with mean 0 and variance $\sigma^{2}$, captures Nature's stochastic impact on $G$. I abstract from country-specific uncertainty.

The other type of stock is technology. The technology stock in country $i$ is measured by $R_{i}$, and it depreciates over time at the rate $1-q_{R} \in[0,1]$. If country $i$ invests $r_{i}$ units in technology, $R_{i}$ increases directly by $d r_{i}$ units and, allowing for technological spillovers, $R_{j}$ may increase by $e r_{i}, \forall j \neq i .^{15}$

$$
R_{i}=q_{R} R_{i,-}+d r_{i}+\sum_{j \neq i} e r_{j} .
$$

Assuming the spillover is imperfect, $d>e$. The total effect on $R \equiv \sum_{i} R_{i}$ is defined by the primitive constant $D \equiv d+e(n-1)$.

With only one type of technology, I cannot distinguish among innovation, development, diffusion, and learning by doing. Thus, several interpretations of $R_{i}$ are consistent with the model. For example, $R_{i}$ may measure $i$ 's abatement technology, i.e., the amount by which $i$ can at no cost reduce (or clean) its potential emissions. If energy production, measured by $y_{i}$, is generally polluting, the actual emission level of country $i$ is given by:

$$
g_{i}=y_{i}-R_{i} .
$$

Alternatively, $R_{i}$ may measure the capacity of country $i$ 's renewable energy sources (or "windmills"). If the windmills can generate $R_{i}$ units of energy, and the alternative is to use polluting fossil fuels, the total amount of energy produced is given by $y_{i}=g_{i}+R_{i} \Rightarrow$ (3.3).

Relying on (3.3), rather than focusing on technologies that reduce the emission content of each produced unit (e.g., $g_{i}=y_{i} / R_{i}$ ), simplifies the analysis tremendously. An equally helpful assumption is to let the investment cost be linear and equal to $K r_{i}$. In reality, the cost of investing in technology can be a convex or a concave function (if there are increasing returns to scale). Imposing linearity is thus a strong assumption, but it permits a tractable model despite the $n+1$ stocks.

Let the benefit of consuming (and producing) energy be given by the increasing and concave function $B\left(y_{i}\right)$. If $C(G)$ is an increasing convex function representing each country's cost of the public bad, $i$ 's utility in a period is:

$$
u_{i}=B\left(y_{i}\right)-C(G)-K r_{i} .
$$

Remarks on $\theta$ : The stochastic shock $\theta$ has a minor role in the model and most of the results hold without it (i.e., if $\sigma=0$ ). But the future marginal cost of emissions is in

\footnotetext{
${ }^{15}$ Such spillovers are empirically important (Coe and Helpman, 1995).
} 
reality uncertain, and this can be captured by $\theta$. In fact, the model would be identical if the level of greenhouse gases were $\widehat{G} \equiv q_{G} G_{-}+\sum_{i} g_{i}$ and the uncertainty were in the associated cost-function, affecting $C$ but not $\widehat{G}$ :

$$
u_{i}=B\left(y_{i}\right)-C(\widehat{G}+\Theta)-K r_{i}, \text { where } \Theta=q_{G} \Theta_{-}+\theta .
$$

Most results would continue to hold even if the effects of $\widehat{G}$ and $\Theta$ were not additive. ${ }^{16}$ Note that, although $\theta$ is i.i.d. across periods, it has a long-lasting impact through its effect on $G$.

Alternative interpretations: Instead of interpreting $y_{i}$ as "energy," we could substitute (3.3) in $B($.$) and let B\left(g_{i}+R_{i}\right)$ measure $i$ 's direct benefit of adding to the public bad (e.g., due to saved abatement costs). Better technology is then a perfect substitute for producing the public bad. The public bad does not, of course, have to be greenhouse gases. Moreover, by defining a public good as $-G$ and contributions as $-g_{i}$, $i$ 's marginal cost of providing the public good is $B^{\prime}\left(R_{i}-\left(-g_{i}\right)\right)$, increasing in $i$ 's contribution but decreasing in $i$ 's technology. Hence, the model fits many situations (with private provision of public goods or bads) beyond climate change.

\subsection{The Timing}

The investment stages and the pollution stages alternate over time. Somewhat arbitrarily, I define "a period" to be such that the countries first (simultaneously) invest in technology, after which they (simultaneously) decide how much to pollute. In between, $\theta$ is realized. Information is symmetric at all stages.

Country $i$ 's objective is to maximize the present-discounted value of its future utilities,

$$
U_{i}=\sum_{\tau=t}^{\infty} u_{i, \tau} \delta^{\tau-t}
$$

where $\delta$ is the common discount factor and $U_{i}$ is $i$ 's continuation value as measured at the start of period $t$. As mentioned, subscripts denoting period $t$ are often skipped.

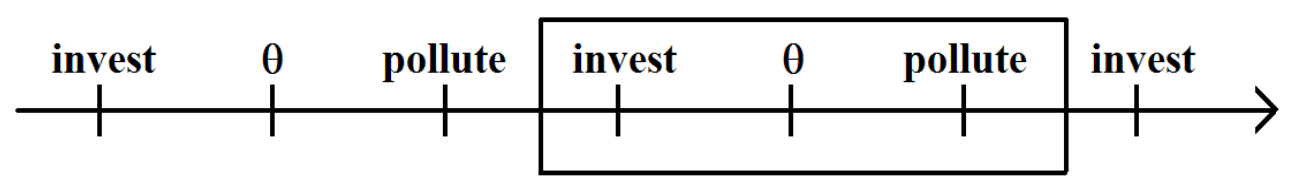

Figure 1: The timing and definition of a period

\subsection{The Equilibrium Concept}

As in most dynamic games with stocks, attention is restricted to Markov perfect equilibria (MPE) as defined by Maskin and Tirole (2001). The MPE turns out to be unique

\footnotetext{
${ }^{16}$ The exceptions are Propositions 3 and 6 where I rely on quadratic utility functions.
} 
and coinciding with the unique subgame-perfect equilibrium if time were finite and approaching infinity. ${ }^{17}$ Maskin and Tirole (2001, pp. 192-3) defend MPEs since they are "often quite successful in eliminating or reducing a large multiplicity of equilibria," and they "prescribe the simplest form of behavior that is consistent with rationality" while capturing that "bygones are bygones more completely than does the concept of subgameperfect equilibrium." While this rules out trigger strategies and related punishments, I will nevertheless consider the possibility that countries can negotiate future emission levels. Although I do not explain why countries comply with such promises, one explanation is that the treaty must be ratified domestically and that certain stakeholders have incentives to sue the government unless it complies. By increasing the possibilities for negotiating and contracting, I derive results for each situation, making a comparison feasible.

If the countries are negotiating, I assume the outcome is efficient and symmetric if the payoff-relevant variables are symmetric across countries. These assumptions are weak and satisfied whether we rely on (i) the Nash Bargaining Solution (with or without side transfers) or (ii) take-it-or-leave-it offers (with side transfers) if each country has the same chance of being recognized as the proposer. All countries participate in equilibrium, since there is no stage at which they can commit to not negotiate with the others.

\section{Analysis}

This section solves the game above, gradually increasing the possibilities for negotiating and contracting. As a reference for the future, the first-best emission level $g_{i}^{*}$ ex post (taking $R, G_{-}$, and $\theta$ as given) satisfies

$$
\begin{aligned}
& B^{\prime}-n C^{\prime}+n \delta U_{G}=0, \text { where } \\
& B^{\prime} \equiv \partial B\left(g_{i}^{*}+R_{i}\right) / \partial g_{i}, C^{\prime} \equiv \partial C(G) / \partial G, U_{G}=-q_{G}\left(1-\delta q_{R}\right) K / D n
\end{aligned}
$$

The first-best investment level is given by

$$
\begin{gathered}
\mathrm{E} B^{\prime}\left(g_{i}+R_{i}^{*}\right)=\frac{K\left(1-\delta q_{R}\right)}{D} \Rightarrow \\
\mathrm{E}^{\prime}(G)=\frac{\left(1-\delta q_{G}\right)\left(1-\delta q_{R}\right) K}{D n} .
\end{gathered}
$$

Expectations are w.r.t. the unknown realization of $\theta$. Combined with (3.1), (4.3) pins down the $\sum_{i} g_{i} \mathrm{~s}$. Given the $g_{i} \mathrm{~s},(4.2)$ determines the first-best $R_{i}^{*} \mathrm{~s}$ which, with (3.2), determine the first-best $r_{i}$ s. Throughout the analysis, I assume $g_{i} \geq 0$ and $r_{i} \geq 0$ never bind. ${ }^{18}$

\footnotetext{
${ }^{17}$ Fudenberg and Tirole (1991, p. 533) suggest that "one might require infinite-horizon MPE to be limits of finite-horizon MPE."

${ }^{18}$ This is satisfied if $g_{i}<0$ and $r_{i}<0$ are allowed, or if $q_{G}$ and $q_{R}$ are sufficiently small.
} 


\subsection{No Agreement}

First, assume that the countries act noncooperatively at every stage. This may be reasonable if the countries cannot commit to future policies because effective sanctions are lacking.

Note that choosing $g_{i}$ is equivalent to choosing $y_{i}$, once the $R_{i}$ s are sunk. Substituting (3.3) into (3.1), we get:

$$
\begin{aligned}
G & =q_{G} G_{-}+\theta+\sum_{i} y_{i}-R, \\
R & \equiv \sum_{i} R_{i}=q_{R} R_{-}+\sum_{i} r_{i} D .
\end{aligned}
$$

This way, the $R_{i}$ s are eliminated from the model: they are payoff-irrelevant as long as $R$ is given, and $i$ 's Markov Perfect strategy for $y_{i}$ is thus not conditioned on them. ${ }^{19} \mathrm{~A}$ country's continuation value $U_{i}$ is thus a function of $G_{-}$and $R_{-}$, not $R_{i,-}-R_{j_{-}-}$, and we can therefore write it as $U\left(G_{-}, R_{-}\right)$, without the subscript $i$.

At the emission stage, when the technologies are sunk, $i$ solves

$$
\begin{gathered}
\max _{y_{i}} B\left(y_{i}\right)-C(G)+\delta U(G, R) \text { s.t. } \quad(4.4) \Rightarrow \\
B^{\prime}-C^{\prime}+\delta U_{G}=0 .
\end{gathered}
$$

First, note that, since (4.6) decreases in $g_{i}$, each country pollutes too much compared to the first best (4.1) when $U_{G}<0$ : a country is not internalizing the cost for the others.

Second, (4.6) confirms that each $i$ chooses the same $y_{i}$, no matter the $R_{i}$ s. While perhaps surprising at first, the intuition is straightforward. Every country has the same preference (and marginal utility) w.r.t. $y_{i}$, and the marginal impact on $G$ is also the same for every country: one more energy unit generates one unit of emissions. ${ }^{20}$

Substituting (4.4) in (4.6) implies that a larger $R$ must increase every $y_{i}$. This implies that if $R_{i}$ increases but $R_{j}, j \neq i$, is constant, then $g_{j}=y_{j}-R_{j}$ must increase. Furthermore, substituting (3.3) in (4.6) implies that if $R_{i}$ increases, $g_{i}$ must decrease. In sum: if country $i$ has better technology, $i$ pollutes less but (because of this) other countries pollute more. Clearly, this effect discourages countries from investing. In addition, the Appendix shows that, in equilibrium, $r_{i}$ increases in $G_{-}$but decreases in $R_{-}$. Thus, a country may want to pollute a lot and invest little today in order to induce the other countries to invest more tomorrow. With these dynamic effects, this common pool problem is more severe than its static counterpart (or the open-loop equilibrium). ${ }^{21}$

Proposition 1: There is a unique symmetric MPE. Countries pollute too much and

\footnotetext{
${ }^{19}$ This follows from the definition by Maskin and Tirole (2001, p. 202), where Markov strategies are measurable with respect to the coarsest partition of histories consistent with rationality.

${ }^{20}$ This follows from (3.3) and would be false if technology affected the marginal emission content of energy production.

${ }^{21}$ This is also the case in Ploeg and de Zeeuw (1991), for example.
} 
invest too little. Furthermore:

$$
\begin{aligned}
y_{i}^{n o} & =y_{j}^{n o} \forall i, j \in\{1, \ldots n\} \forall R_{i}, R_{j}, \\
\partial g_{i}^{n o} / \partial R_{i}< & 0<\partial g_{i}^{n o} / \partial R_{j} \forall j \neq i, \\
\partial r_{i}^{n o} / \partial G_{-}=q_{G} / D n, & \partial r_{i}^{n o} / \partial R_{-}=q_{R} / D n, \\
U_{R}^{n o}=q_{R} K / D n, & U_{G}^{n o}=-q_{G}\left(1-\delta q_{R}\right) K / D n .
\end{aligned}
$$

Conveniently, the continuation value $U$ is linear in $G_{-}$and $R_{-}$. Thus, the $n+1$ stocks collapse to one, making the analysis tractable. This is thanks to (3.3) and the linear investment cost, which also ensures that the equilibrium is unique. ${ }^{22}$ Note that the equilibrium is also stationary.

The dynamic paths are simple. Following a large $\theta$, every country pollutes less and, in the next period, investments increase such that $G_{+}$returns to the original level. The steady state is thus reached in one period.

The size of the externality $e$ has no effect, given $D$. Since only $R$ matters for utilities and strategies, $R_{i}$ becomes a pure public good. ${ }^{23}$

For a given $R$, countries pollute more if $q_{R}$ is large and $K / D$ small. Intuitively, if the technology is efficient, cheap, and long-lasting, one can pollute more today and let this motivate investments in technology tomorrow. This, and other comparative statics can be observed in the Appendix, which derives explicit formulae for the case where $B($.$) and$ $C($.$) are quadratic functions.$

\subsection{Short-term Agreements}

If countries can commit to the immediate but not the distant future, they may negotiate a "short-term agreement." If the agreement is truly short-term, it is difficult for the countries to develop new technology during the time-span of the agreement and the relevant technology is given by historic investments. This interpretation of short-term agreements can be captured by the timing of Figure 2 .

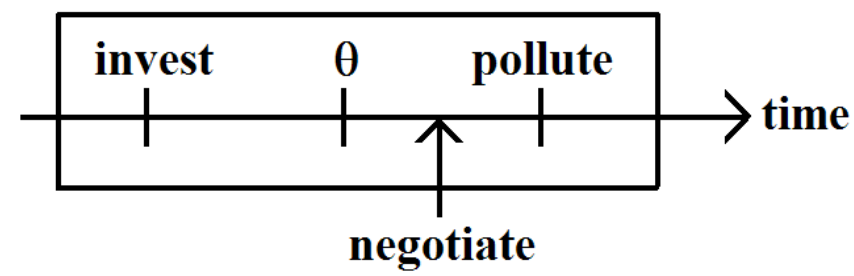

Figure 2: The timing for short-term agreements

\footnotetext{
${ }^{22}$ As the proposition states, this is the unique symmetric MPE. Since the investment cost is linear, there also exist asymmetric MPEs in which the countries invest different amounts. Asymmetric equilibria may not be reasonable when countries are homogeneous, and they would cease to exist if the investment cost were convex. Multiple equilibria never arise under long-term agreements.

${ }^{23}$ Thus, adding to the public good $-G$ (by reducing $g_{i}$ ) or to $R$ (by increasing $r_{i}$ ) has somewhat similar effects. However, they are not equivalent since a larger $r_{i}$ reduces emissions in every future period. Increasing $r_{i}$ thus has longer-lasting impact than reducing $g_{i}$, which is why $r_{i}$ is referred to as an investment. Moreover, the remainder of this section lets $g_{i}$ be contractible while $r_{i}$ is not.
} 
Negotiating the $g_{i}$ s is equivalent to negotiating the $y_{i}$ s as long as the $R_{i}$ s are sunk and observable (even if they are not verifiable). Just as in the previous section, (4.4)-(4.5) imply that the $R_{i}$ s are payoff-irrelevant, given $R$. Even if countries have different $R_{i} \mathrm{~s}$, they face the same marginal benefits and costs of $y_{i}$ whether negotiations succeed or not. Symmetry thus implies that $y_{i}$ is the same for every country in the bargaining outcome. Efficiency implies that the $y_{i}$ s are optimal (all countries agree on this):

$$
\begin{aligned}
B^{\prime}-n C^{\prime}+n \delta U_{G} & =0 \Rightarrow \\
g_{i}^{s t} & =g_{i}^{*},
\end{aligned}
$$

where both $g_{i}^{*}$ and $g_{i}^{s t}$ are functions of existing technology and pollution levels.

Substituting (4.4) in (4.8) and (3.3) in (4.8) implies that if $R_{i}$ increases, $g_{i}$ must decrease - but $g_{j}$ increases, $\forall j \neq i$. Intuitively, if $i$ has better technology, $i$ 's marginal benefit from polluting is less (and $i$ is also polluting less in equilibrium). This gives $i$ a poor bargaining position, and the other countries can offer $i$ a smaller emission quota. At the same time, the other countries negotiate larger quotas for themselves, since the smaller $g_{i}$ (and the smaller $G$ ) reduce the marginal cost of polluting. Anticipating this hold-up problem, every country is discouraged from investing. The Appendix shows $i$ invests until

$$
\mathrm{E} B^{\prime}\left(g_{i}+R_{i}^{s t}\right)=\frac{K\left(n-\delta q_{R}\right)}{D},
$$

so $R_{i}^{s t}$ is smaller than the optimal one, given by (4.2). The equilibrium pollution level is

$$
\mathrm{E} C^{\prime}(G)=\frac{\left(1-\delta q_{G}\right)\left(1-\delta q_{R}\right) K}{D n}+\frac{K(1-1 / n)}{D}
$$

Thus, although emission levels are ex post optimal (4.8), once the investments are sunk, $G$ is larger compared to its first-best level (4.3) since the hold-up problem discourages investments and makes it ex post optimal to pollute more.

Proposition 2: Proposition 1 continues to hold: There is a unique symmetric MPE. Countries pollute too much and invest too little. Furthermore:

$$
\begin{aligned}
y_{i}^{s t} & =y_{j}^{s t} \forall i, j \in\{1, \ldots n\} \forall R_{i}, R_{j}, \\
\partial g_{i}^{s t} / \partial R_{i} & <0<\partial g_{i}^{s t} / \partial R_{j} \forall j \neq i, \\
\partial r_{i}^{s t} / \partial G_{-}=q_{G} / D n, & \partial r_{i}^{s t} / \partial R_{-}=q_{R} / D n, \\
U_{R}^{s t}=q_{R} K / D n, & U_{G}^{s t}=-q_{G}\left(1-\delta q_{R}\right) K / D n .
\end{aligned}
$$

While its intuition is quite different, Proposition 2 is identical to Proposition 1. In particular, $U_{G}$ and $U_{R}$ are exactly the same as in the noncooperative case. This does not imply that $U$ itself is identical in the two cases: its level can be different. But this does imply that in deriving actions and utilities for one period, it is irrelevant whether there will also be a short-term agreement in the next (or any future) period. This makes it convenient to compare short-term agreements to no agreement. 


\subsubsection{Are Short-Term Agreements Good?}

Pollution is less under short-term agreements compared to no agreement. That may not be surprising, since the very motivation for negotiating is to reduce pollution. But what about equilibrium investments and utilities?

Unfortunately, a general comparison is not feasible. But some insight can be generated by assuming $B^{\prime \prime}($.$) and C^{\prime \prime}($.$) are constants:$

$$
B\left(y_{i}\right)=-\frac{b}{2}\left(\bar{y}-y_{i}\right)^{2} \text { and } C(G)=\frac{c}{2} G^{2} .
$$

Parameters $b>0$ and $c>0$ measure the importance of energy and climate change. The bliss point $\bar{y}$ represents the ideal energy level if there were no concern for pollution: no country would produce more than $\bar{y}$ due to the implicit costs of generating, transporting, and consuming energy.

Proposition 3: Under (Q), short-term agreements reduce (i) pollution, (ii) investments, and (iii) utilities if $n$ is large and each period short (i.e., if (4.10) holds):

$$
\begin{aligned}
\mathrm{E} G^{s t} & =\mathrm{E} G^{n o}-\frac{K}{D}\left(\frac{n-1}{b+c}\right)\left(1-\frac{\delta q_{R}}{n}\right), \\
r_{i}^{s t} & =r_{i}^{n o}-\frac{K(n-1)^{2}}{n D^{2}(b+c)}\left(1-\frac{\delta q_{R}}{n}\right), \\
(n-1)^{2}-\left(1-\delta q_{R}\right)^{2} & >\sigma^{2}\left[\frac{(b+c)(b c n D / K)^{2}}{\left(b+c n^{2}\right)(b+c n)^{2}}\right] .
\end{aligned}
$$

Rather than being encouraging, short-term agreements impair the motivation to invest. The reason is the following. Anticipating negotiations, the hold-up problem is exactly as strong as the crowding-out problem in the noncooperative equilibrium: in either case, each country only enjoys $1 / n$ of the total benefits generated by its investments (no matter $e$ ). In addition, when an agreement is expected, $i$ understands that pollution will be reduced. A further decline in emissions, made possible by new technology, is then less valuable. Hence, each country invests less. ${ }^{24}$

Since investments decrease under short-term agreements, utilities can decrease as well. This is the case, in particular, if the period for which the agreement lasts is truly short. If so, $\delta$ and $q_{R}$ are large, while there is not much uncertainty from one period to the next. All changes make (4.10) reasonable, and it always holds when the agreement is very short $(\sigma \rightarrow 0)$. Moreover, (4.10) is more likely to hold if $n$ is large (it always holds if $n \rightarrow \infty)$ : the under-investment problem is then large, it becomes important to increase investments, and this is achieved by having no agreement.

At the emission stage, however, once the investments are sunk, all countries benefit from negotiating an agreement. It is the anticipation of negotiations which reduces investments and perhaps utility. Thus, if (4.10) holds, the countries would have been better off if they could commit to not negotiate short-term agreements. In particular, it may be better to commit to emission levels before the investments occur.

${ }^{24} \mathrm{~A}$ counter-argument is that, if an agreement is expected, it becomes more important to invest to ensure a decent energy consumption level. While this force is smaller under (Q), it could dominate for other functional forms. 


\subsection{Long-term Agreements}

The model can (and will) be used to analyze agreements of any length. If the countries can negotiate and commit to future emission levels, it will be possible to develop technologies within the time-frame of an agreement. The other countries are then unable to hold up the investing country, since the quotas have already been negotiated, at least for the near future.

\subsubsection{One-period Agreements}

This interpretation of "long-term agreements" can be captured simply by letting the countries negotiate the $g_{i} \mathrm{~s}$ in the beginning of each period, before the investments are made. While these agreements last only one period, they are indeed "longer" than the short-term agreements studied in Section 4.2. Moreover, each period can be arbitrarily long in the model, since I have not specified whether the discount factor, for example, is large or small.

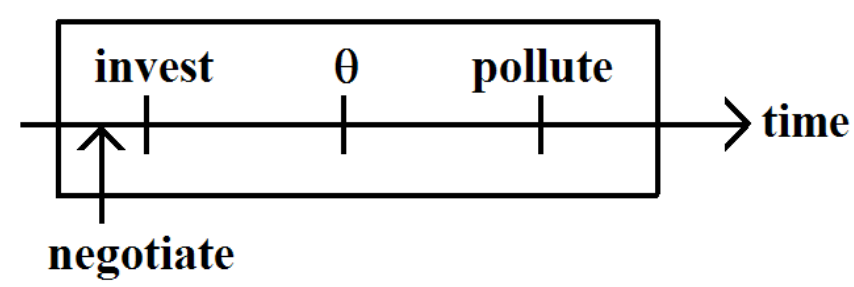

\section{Figure 3: The timing for long-term agreements}

For each period, the timing is now reversed. When investing, a country prefers a larger stock of technology if its quota, $g_{i}^{l t}$, is small, since otherwise it is going to be very costly to comply. Consequently, $r_{i}$ decreases in $g_{i}^{l t}$. The Appendix shows that $r_{i}$ increases until

$$
B^{\prime}\left(g_{i}^{l t}+R_{i}^{l t}\right)=\frac{K\left(1-\delta q_{R} / n\right)}{D-e(n-1)} .
$$

Compared to (4.9), (4.11) suggests that countries invest more under long-term than under short-term agreements (at least for the same $g_{i}$ ). But compared to the first best (4.2), countries still under-invest if $e>0$ or $\delta q_{R}>0$. First, a country does not internalize the spillover $e$ on the other countries. Second, if the agreement does not last forever $(\delta>0)$, a country anticipates that good technology worsen its bargaining position in the future, once a new agreement is to be negotiated. At that stage, good technology leads to a lower $g_{i,+}^{l t}$ since the other countries can hold up $i$ when it is cheap for $i$ to reduce its emissions. ${ }^{25}$ This discourages $i$ from investing now, particularly if the current agreement is relatively short ( $\delta$ large) and the technology likely to survive $\left(q_{R}\right.$ large). In sum, if $e, \delta$, and $q_{R}$ are large, it is important to encourage more investments. This can be achieved by a small $g_{i}^{l t}$.

The Appendix shows that the equilibrium and optimal $g_{i}^{l t}$ s must satisfy (4.3): the equilibrium pollution level is similar to the first best! But since (4.11) implies that the

\footnotetext{
${ }^{25} \mathrm{Or}$, if no agreement is expected in the future, a large $R_{i,+}$ reduces $g_{i,+}$ and increases $g_{j,+}$, as proven in Section 4.1.
} 
equilibrium $R_{i}^{l t} \mathrm{~s}$ are less than optimal, the $g_{i}^{l t} \mathrm{~S}$ are suboptimally low ex post. Combining (4.3) and (4.11):

$$
\begin{aligned}
& B^{\prime}-\mathrm{E} n C^{\prime}-n \delta U_{G}=\frac{K}{D}\left(\frac{e\left(1-\delta q_{R}\right)(n-1)+\delta q_{R}(1-1 / n)}{D-e(n-1)}\right) \Rightarrow \\
& g_{i}^{l t}=\mathrm{E} g_{i}^{*}-\frac{K}{D\left(b+c n^{2}\right)}\left(\frac{e\left(1-\delta q_{R}\right)(n-1)+\delta q_{R}(1-1 / n)}{D-e(n-1)}\right) \text { if }(\mathrm{Q}) .
\end{aligned}
$$

Taking the investments as given, optimally the $g_{i}^{l t}$ should have satisfied $B^{\prime}-\mathrm{E} n C^{\prime}-$ $n \delta U_{G}=0$ rather than (4.12). Only that would equalize marginal costs and benefits of abatement. Relative to this ex post optimal level, the $g_{i}^{l t}$ satisfying (4.12) must be lower. If $e$ and $\delta$ are large, the right-hand side of (4.12) is large, and $g_{i}$ must decline. This makes the long-term agreement more demanding or tougher to satisfy at the emission stage. The purpose of such an overambitious agreement is to encourage investments, since these are suboptimally low when $e$ and $\delta$ are large.

Proposition 4: (i) There is a unique MPE. (ii) Each country invests more if the agreement is tough (4.11). Therefore, (iii) the optimal agreement (4.12) is tougher if the externality $e$ is large and the time horizon short ( $\delta$ large).

On the other hand, if $e=\delta q_{R}=0$, the right-hand side of (4.12) is zero, meaning that the commitments under the best long-term agreement also maximize the expected utility ex post. In this case, there are no externalities, and the countries are not concerned with how current technologies affect future bargaining power. Thus, investments are first best and there is no need to distort the $g_{i}^{l t} \mathrm{~s}$ downwards.

The continuation value $U$ is linear in the stocks, making the analysis tractable. Moreover, $U_{R}^{l t}=q_{R} K / D n$ and $U_{G}^{l t}=-q_{G}\left(1-\delta q_{R}\right) K / D n$, just as in the two previous subsections. The predicted contract and investments are therefore robust to whether there is a long-term agreement, a short-term agreement, or no agreement in the subsequent period.

\subsubsection{Multiperiod Agreements}

Assume now that at the beginning of period 1, countries negotiate the $g_{i, t}$ s for every period $t \in\{1,2, \ldots, T\}$. When investing in period $t \in\{1,2, \ldots, T\}$, countries take the $g_{i, t} \mathrm{~s}$ as given, and the continuation value in period $T+1$ is $U\left(G_{T}, R_{T}\right)$. At the last investment stage, $i$ 's problem is the same as before and $i$ invests until (4.11) holds. Anticipating this, $i$ can invest less in period $T$ by investing more in period $T-1$. The net investment cost is thus $K\left(1-\delta q_{R}\right)$. The same logic applies to every previous period and, in equilibrium,

$$
\mathrm{E}^{\prime}\left(g_{i, t}+R_{i, t}\right)=\frac{K\left(1-\delta q_{R}\right)}{d}=\frac{K\left(1-\delta q_{R}\right)}{D-e(n-1)} \text { for } t<T .
$$

Thus, the incentives to invest are larger earlier than in the last period (4.11). In fact, if $e=0$, investments are first best for every $t<T$. In the last period, however, countries invest less, anticipating the hold-up problem in period $T+1 .^{26}$

\footnotetext{
${ }^{26} \mathrm{Or}$, if no agreement is expected in period $T+1, i$ anticipates $\partial g_{j, T+1} / \partial R_{i}>0, j \neq i$.
} 
All this is anticipated when the countries negotiate the $g_{i, t} \mathrm{~s}$. As shown in the Appendix, the optimal $g_{i, t}$ s must satisfy (4.3) for every $t \leq T$ : the pollution level is similar to the first best! The $g_{i, t} \mathrm{~s}$ are thus lower than what is optimal ex post when $e>0$ and countries under-invest. Combining (4.3) and (4.13) for $t<T$,

$$
\begin{aligned}
& B^{\prime}-\mathrm{E} n C^{\prime}-n \delta U_{G}=\frac{K}{D}\left(\frac{e(n-1)\left(1-\delta q_{R}\right)}{D-e(n-1)}\right) \Rightarrow \\
& g_{i, t}=\mathrm{E} g_{i}^{*}-\frac{K}{D\left(b+c n^{2}\right)}\left(\frac{e(n-1)\left(1-\delta q_{R}\right)}{D-e(n-1)}\right) \text { if }(\mathrm{Q}) .
\end{aligned}
$$

Ex post, $B^{\prime}-n C^{\prime}-n \delta U_{G}=0$ is optimal. Compared to this, $g_{i, t}$ satisfying (4.14) should be smaller if $e$ is positive and large. For $t=T$, however, (4.12) continues to hold and since its right-hand side is less than that of (4.14), $y_{i, T}<y_{i, t}$ for $t<T$. In words: in order to encourage investments, the agreement should be tougher to satisfy toward the end.

Proposition 5: Suppose countries negotiate emission levels for $T$ periods. (i) There is a unique MPE. (ii) Investments decrease toward the end and, to encourage more investments, (iii) the equilibrium agreement becomes tougher over time compared to the ex post optimum (4.12)-(4.14).

\subsubsection{The Optimal Length of an Agreement}

The optimal $T$ trades off two concerns. On the one hand, investments are particularly low just before a new agreement is to be negotiated. This hold-up problem arises less frequently if $T$ is large. On the other hand, the stochastic $\theta$ makes it hard to predict the optimal $g_{i, t}$ for the future, particularly when $T$ is large. If $\theta$ were known or contractible, the agreement should last forever. Otherwise, one can show that the optimal $T$ declines as $e \downarrow 0$. The Appendix derives a large number of comparative statics for the case where $B$ and $C$ are quadratic (Q):

Proposition 6: Under $(Q)$, the agreement's optimal length $T$ increases in the externality $e$ and the number of countries $n$ but decreases in $b, c$, and $\sigma$.

Intuitively, the under-investment problem is particularly severe if $e$ and $n$ are large. Reinforcing this problem by a small $T$ is then especially harmful, and the optimal $T$ is larger. Naturally, $T$ should be smaller if future optimal emissions are uncertain ( $\sigma$ large) and important $\left(c\right.$ large).$^{27}$

\subsection{Long-term Agreements with Renegotiation}

The long-term agreements above are not renegotiation-proof. Not only are the commitments made before the severity of the problem (determined by $\theta$ ) is known, but they also specify emission levels that are less than what is expected to be optimal ex post. The

\footnotetext{
${ }^{27}$ If $b$ is large, consuming energy is much more important than the concern for future bargaining power, the hold-up problem vanishes, and the optimal $T$ is smaller.
} 
countries may thus be tempted to renegotiate the treaty, after $\theta$ and the investments are realized. This section derives equilibria when renegotiation is costless.

\subsubsection{One-period Agreements and Renegotiation}

The timing in each period is now the following. First, the countries negotiate the initial commitments, the $g_{i}^{d e} \mathrm{~s}$, referred to as "the default." If these negotiations fail, it is natural to assume that the threat point is no agreement. ${ }^{28}$ Thereafter, the countries invest and $\theta$ is realized. Before carrying out their commitments, the countries get together and renegotiate the $g_{i}^{d e}$ s. Relative to the threat point $g_{i}^{d e}$, the bargaining surplus is split equally. ${ }^{29}$

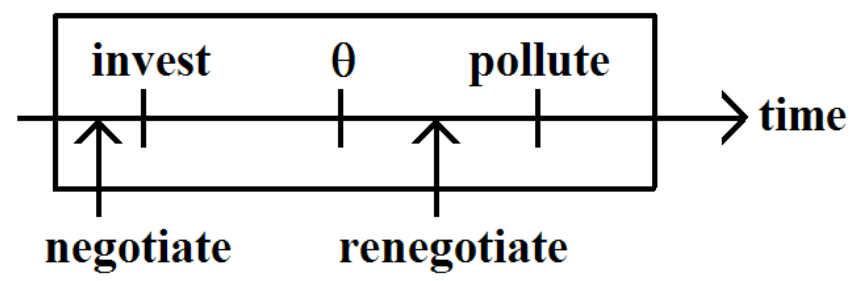

\section{Figure 4: The timing when renegotiation is possible}

Renegotiation ensures that emission levels are ex post optimal, in contrast to the longterm agreements in Section 4.3. When investing, a country anticipates that it will not, in the end, have to comply with an overambitious long-term agreement. Will this jeopardize the incentives to invest?

Proposition 7: (i) There is a unique MPE. (ii) The initial agreement satisfies (4.15): the initial quota $g_{i}^{\text {de }}$ is thus smaller if the spillover $e$ is large and the time horizon short ( $\delta$ large). (iii) All investments and emissions are first best.

$$
\begin{gathered}
B^{\prime}\left(g_{i}^{d e}+R_{i}^{*}\right)=\frac{K}{D-e n} \Rightarrow \\
g_{i}^{d e}=\mathrm{E} g_{i}^{*}-\frac{K}{b D}\left(\frac{e n}{D-e n}+\delta q_{R}\right) \text { under (Q). }
\end{gathered}
$$

When investing, the countries do anticipate that, after renegotiation, emissions will be ex post optimal, just as they were under a short-term agreement. But for the shortterm agreement, countries with the poorest technology got the better deal, since these countries were quite satisfied with the (noncooperative) default outcome in which they could pollute more. This made the "technology-losers" reluctant to negotiate, giving them a better bargaining position. However, things are quite different when renegotiating an

\footnotetext{
${ }^{28}$ If the threat point were short-term agreements, negotiated after the investment stage, the outcome would be identical.

${ }^{29}$ If instead the threat point at the renegotiation stage were that the countries would get upset and revert to no cooperation, the renegotiation game would be identical to negotiations under short-term agreements, and the incentives to invest would be as discussed in Section 4.2.
} 
ambitious agreement. Then, the technology-losers are desperate to reach a new agreement that would replace the initial commitments. Such countries now have a poor bargaining position, and they are, in equilibrium, going to get quite a bad deal (where they must pay or accept a small $g_{i}$ ). Fearing this, the countries are induced to invest more, particularly if the default emission levels are small.

All this will be taken into account when negotiating the initial agreement, the $g_{i}^{d e}$ s. The more ambitious this agreement is, the more the countries invest. This is desirable if the countries are otherwise tempted to under-invest. Thus, the agreement should be more ambitious if $e$ and $\delta q_{R}$ are large. Formally, (4.15) implies that $g_{i}^{d e}$ decreases in $e$ and $\delta q_{R}$ since $R_{i}^{*}$ is increasing in $\delta q_{R}$ but independent of $e$. Intuitively, if the length of the agreement is short, countries fear that more technology today will hurt their bargaining position in the near future. They thus invest less than what is optimal, unless the agreement is more ambitious. ${ }^{30}$

Compared to (4.12), the initial agreement should be tougher than the optimal longterm agreement $\left(g_{i}^{d e}<g_{i}^{l t}\right)$. Intuitively, the long-term agreement (without renegotiation) balances the concern for investments (by reducing $g_{i}^{l t}$ ) and for ex post efficiency (in which $g_{i}$ should be larger). The latter concern is irrelevant when renegotiation ensures ex post optimality, so the initial contract can be tougher - indeed so tough that investments are first best.

\subsubsection{Multiple Periods and Renegotiation}

The first best is implemented by any long-term agreement lasting $T \geq 1$ periods if renegotiation is possible. Suppose an agreement specifies $g_{i, t}^{d e}, t \in\{1, \ldots, T\}$. Investments at $t<T$ are first best if:

$$
B^{\prime}\left(g_{i, t}^{d e}+R_{i}^{*}\right)=\frac{K\left(1-\delta q_{R}\right)}{D-e n} \Rightarrow g_{i, t}^{d e}=\mathrm{E} g_{i, t}^{*}-\frac{K}{b D}\left(\frac{1-\delta q_{R}}{D / e n-1}\right) \text { if (Q). }
$$

Compared to (4.15), $g_{i, t}^{d e}$ is larger when $T>1$ than when $T=1\left(R_{i}^{*}\right.$ is independent of $T$ ). Thus, agreements lasting one period should be more ambitious than if $T>1$, confirming the earlier finding that an agreement should be more ambitious if its length is short.

Proposition 8: Suppose countries negotiate emission levels for $T>1$ periods and renegotiation is possible. At $t<T$, all investment and emission levels are first best if $g_{i, t}^{\text {de }}$ is given by (4.16). $T$ and $g_{i, t^{\prime}}^{d e}, t^{\prime}>t$, are irrelevant. ${ }^{31}$

\footnotetext{
${ }^{30}$ No contract can help if the externality dominates the direct effect $(e \geq d)$, as first pointed out by Che and Hausch (1999) and later generalized by Segal and Whinston (2002).

${ }^{31}$ Since $T$ and $g_{i, t^{\prime}}^{d e}, t^{\prime}>t$, are irrelevant, the predictions are not sharp when renegotiation is feasible. With a small fixed cost of negotiating each $g_{i, t^{\prime}}^{d e}$, however, the unique optimal contract would be described by Proposition 7.
} 


\subsubsection{Implementation}

The optimal $g_{i, t+1}^{d e}$ s depend on $\theta_{t}$ and they must be (re)negotiated after $\theta_{t}$ is realized. But instead of being negotiated at the start of period $t+1$, the $g_{i, t+1}^{d e}$ s may equally well be negotiated just before the emission stage in period $t$, since no information or individual decisions are made in between. At this time, therefore, the countries may negotiate every $g_{i, t+1}^{d e}<\mathrm{E} g_{i, t+1}^{*}$ while simultaneously renegotiating the $g_{i, t}^{d e} \mathrm{~s}$ and replacing them by the optimal $g_{i, t+1}^{*} \mathrm{~s}$, which are expected to be larger than the $g_{i, t}^{d e} \mathrm{~s}$ negotiated in advance. This might be observationally equivalent to a time-inconsistent policy where the countries make ambitious plans for the future, while repeatedly backing down from promises made in the past. But rather than verifying a time-inconsistency problem, this leads to the first best.

COROllary 1: In equilibrium, the countries repeatedly promise to pollute little in the future but when the future arrives, they relax these promises. This procedure implements the first best.

\section{Trade, Tariffs and Intellectual Property Rights}

This section introduces a new externality, relates it to trade agreements and analyzes the effects of and for climate treaties.

Externalities: There are several ways in which spillovers could be formalized, but many of them give similar results to those above. ${ }^{32}$ An alternative (or addition) to the spillover above arises by assuming that $j$ benefits directly by the externality $x r_{i}$ when $i \neq j$ invests. If $K$ continues to be the social net marginal investment cost, $i$ 's private investment cost is

$$
k \equiv K+(n-1) x .
$$

The model is unchanged if we just write the utility as

$$
u_{i}=B\left(y_{i}\right)-C(G)-k r_{i}+\sum_{j \neq i} x r_{j}
$$

The externality $x$ can be interpreted as a general technological spillover (affecting $u_{i}$ and not only $i$ 's environmental technology) or as a spillover that reduces $i$ 's cost of making a particular investment $r_{i}$ (such that the cost is $\left.k r_{i}-\sum x r_{j}\right){ }^{33}$ The Appendix allows for both $e$ and $x$ and finds them to play similar roles.

Trade in technologies: The externality $x$ may reflect international law. Suppose that $r_{i}$ has the potential of reducing $j$ 's cost (or increasing $u_{j}$ ) by $\bar{x} r_{i}$ units. Of this, $j$ can copy a fraction $\gamma \in[0,1]$ for free. The remaining fraction, $1-\gamma$, is available if $j$ pays $i$ for transferring (or licensing) its technology. If $i$ sets the price, $i$ charges $j$ 's willingness to

\footnotetext{
${ }^{32}$ For example, the spillover could be related to $R_{i}$ rather than $r_{i}$ (as in Coe and Helpman, 1995). The results would be similar, but $i$ must then consider the impact of $r_{i}$ on $R_{j}$ not only for the present, but for all future periods.

${ }^{33}$ In fact, the cost would take exactly this form if countries simultaneously choose their targets for the $R_{i} \mathrm{~s}$ and let the expenditures (the $r_{i} \mathrm{~s}$ ) follow residually from (3.2) rather than vice versa.
} 
pay, $(1-\gamma) \bar{x}$, for each invested unit. Clearly, the net externality for $j$ is $x=\gamma \bar{x}$. Weaker intellectual property rights mean larger $\gamma, x$ and $k$.

Firms: Private firms have been ignored so far in the analysis. But since firms may develop most of the technology in reality, it is comforting to note that the results would not necessarily change if firms were introduced. If the government can perfectly regulate the firms' investments in technologies by specifying conditional fees or grants, then firms are perfect agents for the government and it is sufficient to consider the government's incentives. Even without regulation, if the governments are outsourcing the development of technology and firms compete by setting prices, anticipating the revenues $(n-1)(1-\gamma) \bar{x}$ when licensing to foreigners, technological units are provided at cost-price $k$ and firms are not affecting the game.

Tariffs and subsidies: If the foreign individuals or firms paying for the externality $(1-\gamma) \bar{x}$ face an ad valorem tariff $\tau$, they are willing to pay only $(1-\tau)(1-\gamma) \bar{x}$ for each imported unit. On the other hand, since trade is verifiable, one may consider encouraging R\&D by subsidizing trade in abatement technology. ${ }^{34}$ Let $s$ represent this subsidy, paid for by either the importing country or uniformly by the non-exporting countries. In either case, the net externality for country $j$ when country $i$ decides to invest becomes

$$
x=\gamma \bar{x}-(s-\tau)(1-\gamma) \bar{x} .
$$

The private cost of investing faced by a country (or government) is $k$ given by (5.1), just as before. Thus, $k$ and $x$ are both higher with tariffs, since the importing country is then capturing more of the surplus, but lower if importers subsidize technological trade. The role of $s$ would be identical if directed to investments rather than the associated trade.

Proposition 9: If the subsidy $(s)$ is low, tariff $(\tau)$ high and the intellectual property rights weak ( $\gamma$ large), ( $i)$ the agreement should be tougher and more long-lasting while (ii) short-term agreements are likely to be worse than no agreement under $(Q)$.

While the proof is in the Appendix, the intuition is straightforward. With tariffs, small subsidies and weak property right protection, firms do not capture the benefit experienced by the foreigners. This forces the government to pay more to compensate the firms when investing, and they invest less. A further reduction in investment is then particularly bad, making short-term agreements worse than the noncooperative equilibrium (under $(\mathrm{Q})$ ). To encourage more investments, it is better to negotiate an agreement that is tougher and more long-lasting.

If $s, \tau$ or $\gamma$ can be specified by international law, one may ask what their levels should be. Does the optimal subsidy, tariff and intellectual property right protection depend on the climate treaty?

Proposition 10: s should be larger while $\tau$ and $\gamma$ smaller if the agreement is shortlasting. The optimal $s, \tau$ and $\gamma$ are given by (5.2) for short-term agreements, (5.3) for long-term agreements (and the last period of multiperiod agreements), and by (5.4) for

\footnotetext{
${ }^{34}$ Stern $(2007$, p. 398) states "There are two types of policy response to spillovers... enforcement of private property rights through patenting [and] government funding."
} 
multiperiod agreements (except for the last period).

$$
\begin{aligned}
\left(s^{s t}-\tau^{s t}\right)\left(1-\gamma^{s t}\right)-\gamma^{s t} & =\frac{K}{n \bar{x}}> \\
\left(s^{l t}-\tau^{l t}\right)\left(1-\gamma^{l t}\right)-\gamma^{l t} & =\frac{K}{n \bar{x}}\left(\delta q_{R}+\frac{e n}{D}\left(1-\delta q_{R}\right)\right)> \\
\left(s^{t}-\tau^{t}\right)\left(1-\gamma^{t}\right)-\gamma^{t} & =\frac{K e}{\bar{x} D} .
\end{aligned}
$$

It is more important to encourage investments by protecting intellectual property rights, subsidizing technological trade and reducing tariffs if the climate treaty is shortlasting, since the hold-up problem is then larger. Such "trade agreements" are thus strategic substitutes to climate treaties: Weakening cooperation on one area makes further cooperation on the other more important.

If the subsidy can be freely chosen, short-term agreements are first best: while (5.2) induces optimal investments, countries are negotiating the ex post optimal emissions. The emission levels under long-term agreements (without renegotiation) are never first best, however, due to the stochastic $\theta$.

COROLlary 2: If s can be freely chosen, short-term agreements are first best while longterm agreements (without renegotiation) are not.

If renegotiation is possible, the first best is feasible no matter $s, \tau$ and $\gamma$ as long as the initial agreement is more ambitious for large $e$ and $x$ (and thus large $\gamma$ and $\tau$ but small $s)$. Under $(\mathrm{Q})$, the $g_{i}^{d e}$ s should satisfy ${ }^{35}$

$$
g_{i}^{d e}=\mathrm{E} g_{i}^{*}-\frac{K}{b D}\left(\frac{x / K+e / D}{1 / n-e / D}+\delta q_{R}\right) .
$$

If the $g_{i}^{d e}$ s are exogenously given and high (e.g. because a tough climate treaty would be impossible to enforce), efficiency and (5.5) are still fulfilled if just $x$ is sufficiently small (requiring a large $s$ and small $\tau$ or $\gamma$ ). This suggests that less ambitious climate treaties should be accompanied by technological subsidies, low tariffs and property right protection, confirming that the two types of agreements are strategic substitutes.

COROLlary 3: With renegotiation, the first best is implemented even if $g_{i}^{\text {de }}$ increases, if just $s$ increases or $\tau$ or $\gamma$ decreases.

\section{Generalizations and Extensions}

\subsection{Tradable Permits}

To simplify intuition and the reasoning, it has been assumed that quotas cannot be traded. This is not a critical assumption, however.

\footnotetext{
${ }^{35}$ The general conditions are derived in the Appendix.
} 
Proposition 11: (i) All results survive with tradable permits, no matter whether side payments are available. (ii) The equilibrium and optimal permit price is $B^{\prime}$, thus increasing in $e$ and larger if $T=1$ than if $T>1$.

$B^{\prime}\left(g_{i}+R_{i}\right)$ is the value of being allowed to pollute one more unit, keeping $G$ and $R$ constant. Proposition 11 follows by noting that, first, there is never any trade in permits in equilibrium. Hence, if $i$ invests as above, the marginal benefit of more technology is the same. Second, if $i$ deviated by investing more (less), it's marginal utility of a higher technology decreases (increases) not only when permit-trade is prohibited, but also when trade is allowed since more (less) technology decreases (increases) the demand for permits and thus the equilibrium price. Hence, such a deviation is not attractive. When permits are tradable, altering their allocation is a form of side transfer, making the feasibility of explicit transfers irrelevant. ${ }^{36,37}$

\subsection{Heterogeneity}

So far, countries have been completely symmetric and there has been no heterogeneity. It did turn out, however, that for a given $R_{-}$, differences in $R_{i,-}$ ( $\operatorname{such}$ as $R_{i,-}-R_{j,-}$ ) were payoff-irrelevant. It is therefore not necessary to assume that all countries start out with the same technology.

Moreover, since the continuation values are linear in $R$, countries are risk-neutral in that it would not matter if $q_{R}$ were random, as long as the expected depreciation rate is $1-q_{R}$. The realized depreciation can also be different for every country, as long as the expected depreciation rate is $1-q_{R}$ for everyone.

A strong assumption has been that all countries had identical preferences. With quadratic utility functions, for example, it is reasonable to assume that countries have different bliss points $\left(\bar{y}_{i}\right)$ for energy consumption. Generalizing the quadratic specification, we may write the benefit function as $B\left(y_{i}-\bar{y}_{i}\right)$, where $\bar{y}_{i}$ is a country-specific reference point (not necessarily bliss). Recognizing the importance of such heterogeneity, all proofs allow the reference point $\bar{y}_{i}$ to vary. While a large $\bar{y}_{i}$ increases the equilibrium $g_{i}$, the comparative statics are unchanged. ${ }^{38}$

\footnotetext{
${ }^{36}$ In a two-stage model, also Golombek and Hoel (2005) find that the permit price should be higher than "the Pigouvian" level to induce R\&D when there are spillovers.

${ }^{37}$ An earlier version of this paper analyzed emission taxes and derived similar results: for example, the first best is feasible with renegotiation if the initial tax is higher than what is expected to be optimal ex post, particularly if the spillover is large and the agreement's length relatively short.

${ }^{38}$ Other types of heterogeneity would be harder to analyze. For example, suppose the cost of developing technology, $K$, varied across countries. In equilibrium, only countries with a small $K$ would invest. This would also be optimal, but, just as before, the investing countries would invest too little. In a long-term agreement, one could encourage these countries to invest more by reducing $g_{i}^{l t}$ or, if renegotiation is possible, $g_{i}^{d e}$. Such small $g_{i}$ s would not be necessary (or optimal) for noninvesting countries. Naturally, the investing countries would require some compensation to accept the optimal emission targets. At the same time, a small $g_{i}$ would not motivate $i$ to invest if $i$ were allowed to purchase permits from noninvesting countries with higher $g_{j}$ s. Thus, with heterogeneity in investment costs, it matters a great deal whether side transfers are possible and permits tradable: Proposition 11 would be false if such heterogeneity were introduced. Evaluating political instruments under heterogeneity is thus an important task for future research.
} 
Proposition 12: All results continue to hold with heterogenous bliss or reference points in $B\left(y_{i}-\bar{y}_{i}\right)$.

\section{Conclusions}

This paper presents a novel dynamic game where $n$ players contribute to a public bad while also investing in cost-reducing technologies. By assuming linear investment costs, the Markov perfect equilibrium (MPE) is unique, the continuation value linear, and the analysis tractable, despite the $1+n$ stocks. While the unique equilibrium rules out selfenforcing agreements, the framework can be employed to analyze incomplete contracts in a dynamic setting. I derive the optimal contract as a function of its length, and the optimal length is discussed. When renegotiation is possible, I characterize contracts implementing the first best.

While the method and the model are general, the assumptions are motivated by climate change and the implications for a treaty are important. First, agreements are not necessarily good. In particular, one should be careful when recommending short-term agreements since investments may fall. Second, an agreement should be more ambitious if its length is short. Although perhaps counterintuitive at first, this is required to motivate investments in new technology. Third, the agreement should be tougher and longer-term if the technological spillover is large. Since spillovers are particularly large if intellectual property rights are weak and tariffs large, treaties for climate and trade might be strategic substitutes. Fourth, if $R \& D$ can be subsidized internationally, the optimal subsidy is larger if the agreement is short-term. Finally, flexibility regarding future emission levels are best ensured by renegotiating long-term agreements rather than by letting them expire quickly. Since the commitments under the Kyoto Protocol expire in 2012, the current default is no agreement at all. On the other hand, when the Doha-round trade negotiations broke down, countries did not revert to the noncooperative equilibrium but to the existing set of trade agreements. The procedure used for trade is more efficient than the one currently used for climate, according to the above analysis.

The results hold whether side transfers are available, permits tradable, firms included, and whether the technology can be traded, taxed, or subsidized. Nevertheless, this paper is only one step toward a better understanding of good environmental agreements. I have not distinguished between technological innovation and diffusion, and I have abstracted from domestic politics, heterogeneity, private information, monitoring, compliance, coalition formation and the possibility of opting out of the agreement. Relaxing these assumptions are the natural next steps. 


\section{Appendix}

All propositions are here proven with the generalizations discussed in Sections 5-6: the value of $y_{i}$ is given by the increasing and concave function $\beta\left(y_{i}-\bar{y}_{i}\right)$, countries can have different reference points $\bar{y}_{i}$, and $r_{i}$ generates a direct externality $x=\epsilon-s /(n-1)$ on $j \neq i$ in addition to the technological spillover $e$ :

$$
u_{i}=\beta\left(y_{i}-\bar{y}_{i}\right)-C(G)-k r_{i}+x \sum_{j \neq i} r_{j} .
$$

In Sections 3 and $4, B\left(y_{i}\right) \equiv \beta\left(y_{i}-\bar{y}\right)$ since $\bar{y}_{i}=\bar{y}$, and $x=0 \Rightarrow k=K$.

While $U_{i}$ is the continuation value just before the investment stage, let $W_{i}$ represent the (interrim) continuation value at (or just before) the emission stage. To shorten equations, use $m \equiv-\delta \partial U_{i} / \partial G_{-}, z \equiv \delta \partial U_{i} / \partial R_{-}, \widetilde{R} \equiv q_{R} R_{-}, \widetilde{G} \equiv q_{G} G_{-}+\theta$ and $\widetilde{y}_{i} \equiv y_{i}+\bar{y}-\bar{y}_{i}$, where $\bar{y}$ is the average $\bar{y}_{i}$. Note that by substitution,

$$
\begin{aligned}
G & =\widetilde{G}+\sum_{i} y_{i}-\sum_{i} R_{i}=q_{g} G_{-}+\sum_{i} \widetilde{y}_{i}-R, \text { and } \\
u_{i} & =B\left(y_{i}-\bar{y}_{i}\right)-C(G)-k r_{i}+x \sum r_{j}=B\left(\widetilde{y}_{i}-\bar{y}\right)-C(G)-k r_{i}+x \sum r_{j} .
\end{aligned}
$$

All $i$ 's are identical w.r.t. $\widetilde{y}_{i}$. The game is thus symmetric, no matter differences in $R_{i}$ or $\bar{y}_{i}$, and the payoff relevant states are $G$ and $R$. Analyzing the symmetric equilibrium (where symmetric countries invest identical amounts), I drop the subscript for $i$ on $U$ and $W$. The proof for the first best (4.1)-(4.3) is omitted since it would follow the same lines as the following proof.

\subsection{Proof of Proposition 1}

At the emission stage, each country's first-order condition for $y_{i}$ is:

$$
\begin{aligned}
0 & =\beta^{\prime}\left(y_{i}-\bar{y}_{i}\right)-C^{\prime}(G)+\delta U_{G}(G, R) \\
& =\beta^{\prime}\left(\widetilde{y}_{i}-\bar{y}\right)-C^{\prime}\left(\widetilde{G}-R+\sum \widetilde{y}_{i}\right)+\delta U_{G}\left(\widetilde{G}-R+\sum \widetilde{y}_{i}, R\right),
\end{aligned}
$$

implying that all $\widetilde{y}_{i}$ s are identical and implicit functions of $\widetilde{G}$ and $R$ only. At the investment stage, $i$ maximizes:

$$
\mathrm{E} W(\widetilde{G}, R)-k r_{i}=\mathrm{E} W\left(q_{G} G_{-}+\theta, \widetilde{R}+\sum_{i} D r_{i}\right)-k r_{i},
$$

implying that $R$ is going to be a function of $G_{-}$, given implicitly by $\mathrm{E} \partial W\left(q_{G} G_{-}+\right.$ $\theta, R) / \partial R=k / D$ and explicitly by, say, $R\left(G_{-}\right)$. In the symmetric equilibrium, each country invests $\left(R\left(G_{-}\right)-q_{R} R_{-}\right) / D n$. Thus:

$$
\begin{aligned}
U\left(G_{-}, R_{-}\right) & =\mathrm{E} W\left(q_{G} G_{-}+\theta, R\left(G_{-}\right)\right)-(k-(n-1) x)\left(\frac{R\left(G_{-}\right)-q_{R} R_{-}}{D n}\right) \Rightarrow \\
z / \delta & \equiv \frac{\partial U}{\partial R_{-}}=\frac{q_{R} K}{D n}
\end{aligned}
$$


in every period. Hence, $U_{R G}=U_{G R}=0, m$ and $U_{G}$ cannot be functions of $R$ and (8.1) implies that $\widetilde{y}_{i}, G$ and thus $\beta\left(\widetilde{y}_{i}-\bar{y}\right)-C(G) \equiv \gamma($.$) are functions of \widetilde{G}-R$ only. Hence, write $G(\widetilde{G}-R)$. (8.2) rewritten:

$$
\mathrm{E} \gamma\left(q_{G} G_{-}+\theta-R\right)-k r_{i}+\delta U\left(G\left(q_{G} G_{-}+\theta-R\right), R\right)
$$

and because $U_{R}$ is a constant, maximizing this w.r.t. $r_{i}$ makes $q_{G} G_{-}-R$ a constant, say $\xi$. This gives $\partial r_{i} / \partial G_{-}=q_{G} / D n$ and $U$ becomes:

$$
\begin{aligned}
U\left(G_{-}, R_{-}\right) & =\mathrm{E} \gamma(\xi+\theta)-K r+\delta U(G(\xi+\theta), R) \\
& =\mathrm{E} \gamma(\xi+\theta)-K\left(\frac{q_{G} G_{-}-\xi-q_{R} R_{-}}{D n}\right)+\delta U\left(G(\xi+\theta), q_{G} G_{-}-\xi\right) \Rightarrow \\
m / \delta & =\partial U / \partial G_{-}=-K\left(\frac{q_{G}}{D n}\right)+\delta U_{R} q_{G}=-\frac{K q_{G}}{D n}\left(1-\delta q_{R}\right),
\end{aligned}
$$

since $G(\xi+\theta)$ and $\gamma($.$) are not functions of G_{-}$when $q_{G} G_{-}-R=\xi$. Since $U_{G}$ is a constant, (8.1) implies that if $R$ increases, $\widetilde{y}_{i}$ increases but $G$ must decrease. Thus, $\partial \widetilde{y}_{i} / \partial R \in(0,1)$, so $\partial g_{i} / \partial R_{j}=\partial\left(\widetilde{y}_{i}-\bar{y}_{i}+\bar{y}-R_{i}\right) / \partial R_{j}>0$ if $i \neq j$ and $<0$ if $i=j$.

Under (Q), (8.1) becomes

$$
\begin{aligned}
0 & =-c G+b \bar{y}_{i}-b y_{i}-m \Rightarrow y_{i}=\bar{y}_{i}-\frac{m+c G}{b} . \\
G & =\sum_{j}\left(y_{j}-R_{j}\right)+\widetilde{G}=\widetilde{G}+n\left(\bar{y}-\frac{m+c G}{b}\right)-\sum_{j} R_{j} \Rightarrow \\
G & =\frac{b \bar{y} n-m n+b(\widetilde{G}-R)}{b+c n}, \text { so } \\
y_{i} & =\bar{y}_{i}-\frac{m}{b}-\frac{c}{b}\left(\frac{b \bar{y} n-m n+b(\widetilde{G}-R)}{b+c n}\right)=\left(\bar{y}_{i}-\bar{y}\right)+\frac{b \bar{y}-m-c(\widetilde{G}-R)}{b+c n} \text { and } \\
g_{i} & =y_{i}-R_{i}=\left(\bar{y}_{i}-\bar{y}\right)+\frac{b \bar{y}-m-c\left(\widetilde{G}-\sum_{j \neq i} R_{j}\right)}{b+c n}-\frac{R_{i}(b+c n-c)}{b+c n} .
\end{aligned}
$$

Interrim utility (after investments are sunk) can be written as:

$$
\begin{aligned}
W_{i}^{n o} & \equiv-c(1+c / b) G^{2} / 2-G m c / b+\frac{(b \bar{y})^{2}-m^{2}}{2 b}+\delta U(G, R) . \text { Thus, } \\
\partial W_{i}^{n o} / \partial R & =c(1+c / b) G\left(\frac{b}{b+c n}\right)+\frac{b m(1+c / b)}{b+c n}+z .
\end{aligned}
$$


At the investment stage, each country sets $k / D=\mathrm{E} \partial W_{i}^{n o} / \partial R$. From (8.7):

$$
\begin{aligned}
k / D & =\mathrm{E} c(G)\left(\frac{b+c}{b+c n}\right)+\frac{m(b+c)}{b+c n}+z \Rightarrow \\
\mathrm{E} G & =\frac{k(b+c n)}{c D(b+c)}-\frac{m}{c}-\frac{z}{c}\left(\frac{b+c n}{b+c}\right), \text { combined with (8.6): } \\
R & =q_{G} G_{-}+n \bar{y}-n m / b-\frac{b+c n}{b} \mathrm{E} G \\
& =q_{G} G_{-}-\frac{k(b+c n)^{2}}{D c b(b+c)}+\bar{y} n+\frac{z(b+c n)^{2}}{c b(b+c)}+\frac{m}{c} \Rightarrow \\
r_{i} n D & =-q_{R} R+q_{G} G_{-}-\frac{k(b+c n)^{2}}{D c b(b+c)}+\bar{y} n+\frac{z(b+c n)^{2}}{c b(b+c)}+\frac{m}{c} .
\end{aligned}
$$

Since $\widetilde{G}=q_{G} G_{-}+\theta,(8.6)$ gives $G=\mathrm{E} G+\theta b /(b+c n)$. Substituting in (8.5) and (8.8):

$$
y_{i}=\bar{y}_{i}-\frac{m+c G}{b}=\bar{y}_{i}-\frac{(k / D-z)(b+c n)}{b(b+c)}-\frac{\theta c}{b+c n} .
$$

This is helpful when calculating $u_{i}^{n o}$ :

$$
\begin{aligned}
u_{i}^{n o}= & -\frac{c}{2}\left(\frac{k(b+c n)}{D c(b+c)}-\frac{m}{c}-\frac{z(b+c n)}{c(b+c)}+\frac{\theta b}{b+c n}\right)^{2}-\frac{b}{2}\left(\frac{(k / D-z)(b+c n)}{b(b+c)}+\frac{\theta b c}{b(b+c n)}\right)^{2} \\
& -\frac{K}{D n}\left(-\widetilde{R}+q_{G} G_{-}-\frac{k(b+c n)^{2}}{D c b(b+c)}+\bar{y} n+\frac{z(b+c n)^{2}}{c b(b+c)}+\frac{m}{c}\right) \Rightarrow \\
\mathrm{E} u_{i}^{n o}= & -\frac{1}{2}\left(\frac{k}{D}-z\right)^{2}\left(\frac{b+c n}{b+c}\right)^{2}\left(\frac{1}{c}+\frac{1}{b}\right)-\frac{m^{2}}{2 c}+\frac{m}{c}\left(\frac{b+c n}{b+c}\right)\left(\frac{k}{D}-z\right) \\
& -\frac{K}{D n}\left(q_{G} G_{-}-\widetilde{R}-\frac{(b+c n)^{2}}{b c(b+c)}\left(\frac{k}{D}-z\right)+\bar{y} n+\frac{m}{c}\right)-\frac{b c(b+c) \sigma^{2}}{2(b+c n)^{2}} .
\end{aligned}
$$

\subsection{Proof of Proposition 2}

At the emission stage, the countries negotiate the $g_{i}$ s. $g_{i}$ determines $\widetilde{y}_{i}$, and since countries have symmetric preferences over $\widetilde{y}_{i}$ (in the negotiations as well as in the default outcome) the $\widetilde{y}_{i}$ s must be identical in the bargaining outcome and efficiency (8.1) requires:

$$
0=\beta^{\prime}\left(\widetilde{y}_{i}-\bar{y}\right) / n-C^{\prime}\left(\widetilde{G}-R+\sum \widetilde{y}_{i}\right)+\delta U_{G}\left(\widetilde{G}-R+\sum \widetilde{y}_{i}, R\right) .
$$

The rest of the previous proof continues to hold: $R$ will be a function of $G_{-}$only, so $U_{R_{-}}=q_{R} K / D n$. This makes $\mathrm{E} \widetilde{G}-R$ a constant and $U_{G_{-}}=-q_{G}\left(1-\delta q_{R}\right) K / D n$, just as before. The comparative static becomes the same, but the levels of $g_{i}, y_{i}, r_{i}, u_{i}$ and $U_{i}$ are obviously different from the previous case. 
The envelope theorem can be used to calculate equilibrium investments:

$$
\begin{aligned}
\max _{r_{i}} \mathrm{E} \frac{1}{n}\left[\max _{\left\{\widetilde{y}_{j}\right\}} \sum_{j} \beta\left(\widetilde{y}_{j}-\bar{y}\right)-C(G)+\delta U(G, R)\right]-k r_{i} & \Rightarrow \\
\mathrm{E}^{\prime}(G) D-\mathrm{E} \delta U_{G} D+\mathrm{E} \delta U_{R} D-k & = \\
\mathrm{E} C^{\prime}(G) D-\left(1-\delta q_{G}\right)\left(1-\delta q_{R}\right) K / n-(K+x n)(1-1 / n) & =0 .
\end{aligned}
$$

Combined with (8.10),

$$
\begin{aligned}
\frac{\left(1-\delta q_{G}\right)\left(1-\delta q_{R}\right) K}{D n+\frac{(K+x n)(1-1 / n)}{D}} & =\frac{\mathrm{E} \beta^{\prime}\left(\widetilde{y}_{i}-\bar{y}\right)}{n}+\delta U_{G} \Rightarrow \\
\frac{\left(n-\delta q_{R}\right) K}{D}+\frac{n(n-1) x}{D} & =\frac{\mathrm{E} \beta^{\prime}\left(\widetilde{y}_{i}-\bar{y}\right)}{n} .
\end{aligned}
$$

Under (Q), the first-order conditions for the optimal $\widetilde{y}_{i}$ s:

$$
\begin{aligned}
0 & =-n c G+b \bar{y}-b \widetilde{y}_{i}-n m \Rightarrow \widetilde{y}_{i}=\bar{y}-\frac{n m+n c G}{b} . \\
G & =\sum_{j}\left(y_{j}-R_{j}\right)+\widetilde{G}=\widetilde{G}+n\left(\bar{y}-\frac{n m+n c G}{b}\right)-R \Rightarrow \\
G & =\frac{b \bar{y} n-m n^{2}+b(\widetilde{G}-R)}{b+c n^{2}}, \text { so } \\
y_{i} & =\bar{y}_{i}-\bar{y}+\frac{b \bar{y}-m n-c n(\widetilde{G}-R)}{b+c n^{2}} \text { and } \\
g_{i} & =\bar{y}_{i}-\bar{y}+\frac{b \bar{y}-m n-c n(\widetilde{G}-R)}{b+c n^{2}}-R_{i} .
\end{aligned}
$$

Interrim utility is

$$
\begin{aligned}
W_{i}^{s t} & =-\frac{c}{2} G^{2}-\frac{b}{2}\left(\frac{n m+n c G}{b}\right)^{2}+\delta U(G, R), \text { so } \\
\partial W_{i}^{s t} / \partial R & =c G+m+z .
\end{aligned}
$$

A country invests until the marginal costs of investment is

$$
k=D(\mathrm{E} c G+m+z) \Rightarrow \mathrm{E} G=\frac{k}{c D}-\frac{m+z}{c} .
$$

Subsituting in (8.11), after taking the expection of it, and solving for $R$ gives

$$
R=q_{G} G_{-}+n \bar{y}+\frac{m}{c}-\left(\frac{b+c n^{2}}{b}\right)\left(\frac{k}{c D}-\frac{z}{c}\right) .
$$


From (8.12) and (8.13):

$$
\begin{aligned}
G= & \frac{k}{c D}-\frac{m+z}{c}+\frac{b \theta}{b+c n^{2}} \Rightarrow \\
\bar{y}-\widetilde{y}_{i}= & \frac{n m}{b}+\frac{n c}{b}\left(\frac{k}{c D}-\frac{m+z}{c}+\frac{b \theta}{b+c n^{2}}\right)=\frac{n}{b}\left(\frac{k}{D}-z+\frac{b c \theta}{b+c n^{2}}\right) \Rightarrow \\
u_{i}^{s t}= & -\frac{c}{2} G^{2}-\frac{b}{2}\left(\bar{y}-\widetilde{y}_{i}\right)^{2}-K r \\
= & -\frac{c}{2}\left(\frac{k}{c D}-\frac{m+z}{c}+\frac{\theta b}{b+c n^{2}}\right)^{2}-\frac{n^{2}}{2 b}\left(\frac{k}{D}-z+\frac{\theta b c}{b+c n^{2}}\right)^{2}-K r \Rightarrow \\
\mathrm{E} u_{i}^{s t}= & -\frac{1}{2}\left(\frac{k}{D}-z\right)^{2}\left(\frac{1}{c}+\frac{n^{2}}{b}\right)-\frac{m^{2}}{2 c}+\frac{m(k / D-z)}{c} \\
& -\frac{K}{n D}\left(q_{G} G_{-}-q_{R} R_{-}+n \bar{y}+\frac{m}{c}-\left(\frac{b+c n^{2}}{b}\right)\left(\frac{k}{c D}-\frac{z}{c}\right)\right)-\frac{\sigma^{2} b c}{2\left(b+c n^{2}\right)} .
\end{aligned}
$$

\subsection{Proof of Proposition 3}

Comparing (8.9) with (8.14) and (8.8) with (8.15),

$$
\begin{aligned}
& R^{n o}-R^{s t}=-\frac{k(b+n c)^{2}}{D b c(b+c)}+\frac{z(b+n c)^{2}}{b c(b+c)}+\left(\frac{b+c n^{2}}{b}\right)\left(\frac{k}{c D}-\frac{z}{c}\right) \\
&= \frac{k(n-1)^{2}}{D(b+c)}\left(1-\frac{\delta q_{R} K}{n k}\right)>0 . \\
& G^{n o}-\mathrm{E} G^{s t}=\left(\frac{k}{c D}-\frac{z}{c}\right)\left(\frac{b+n c}{b+c}-1\right)=\frac{k}{D}\left(\frac{n-1}{b+c}\right)\left(1-\frac{\delta q_{R} K}{n k}\right)=\frac{R^{n o}-R^{s t}}{n-1}>0 . \\
& \mathrm{E} u_{i}^{s t}-\mathrm{E} u_{i}^{n o}=-\frac{1}{2}\left(\frac{k}{D}-z\right)^{2}\left(\frac{1}{c}+\frac{n^{2}}{b}-\left(\frac{1}{c}+\frac{1}{b}\right)\left(\frac{b+n c}{b+c}\right)^{2}\right)+m \frac{k-z D}{c D}\left(1-\frac{b+n c}{b+c}\right) \\
&-\frac{K}{D n}\left(\frac{k}{D}-z\right)\left(\frac{(b+n c)^{2}}{b c(b+c)}-\frac{b+c n^{2}}{b c}\right)+\frac{\sigma^{2} b c}{2}\left(\frac{b+c}{(b+c n)^{2}}-\frac{1}{b+c n^{2}}\right) \\
&=\left(\frac{\sigma^{2} b c}{2(b+n c)^{2}\left(b+c n^{2}\right)}-\frac{(k / D-z)^{2}}{2 b c(b+c)}+\frac{K}{D n b c(b+c)}\left(\frac{k}{D}-z\right)\right) \\
& \bullet\left[(b+c)\left(b+c n^{2}\right)-(b+n c)^{2}\right]-\frac{m(k / D-z)}{b+c}(n-1) \\
&=\left(\frac{(b c \sigma[n-1])^{2}}{2(b+n c)^{2}\left(b+c n^{2}\right)}-\frac{(k / D-z)[n-1]^{2}}{2(b+c)}\left[\frac{k}{D}-z-\frac{2 K}{D n}\right]\right)-\frac{m(k / D-z)(n-1)}{(b+c)} .
\end{aligned}
$$


Thus, we get $U^{s t}>U^{n o}$ if

$$
\begin{aligned}
& \mathrm{E} u_{i}^{s t}-\mathrm{E} u_{i}^{n o}+m \frac{(k / D-z)(n-1)}{(b+c)}-z \frac{k(n-1)^{2}}{D(b+c)}\left(1-\frac{\delta q_{R} K}{n k}\right)= \\
& \left(\frac{(b c \sigma)^{2}[n-1]^{2}}{2(b+n c)^{2}\left(b+c n^{2}\right)}-\frac{[n-1]^{2}}{2(b+c)}\left[\left(\frac{k}{D}-z\right)^{2}-\frac{2 K}{D n}\left(\frac{k}{D}-z\right)+\frac{2 z k}{D}\left(1-\frac{\delta q_{R} K}{n k}\right)\right]\right)>0 \\
& \Rightarrow \frac{(b c \sigma)^{2}(b+c)}{(b+n c)^{2}\left(b+c n^{2}\right)}>\left(\frac{K}{D}\right)^{2}\left[\left(\frac{k}{K}\right)^{2}+\left(\frac{\delta q_{R}}{n}\right)^{2}-\frac{2 k}{n K}+\frac{2 \delta q_{R}}{n^{2}}-\frac{2\left(\delta q_{R}\right)^{2}}{n^{2}}\right] \\
& =\left(\frac{K}{D}\right)^{2}\left[\left(\frac{K+(n-1) x}{K}\right)^{2}-\left(\frac{\delta q_{R}}{n}\right)^{2}-\frac{2(K+(n-1) x)}{n K}+\frac{2 \delta q_{R}}{n^{2}} \pm \frac{1}{n^{2}}\right] \\
& =\left(\frac{K}{D n}\right)^{2}\left[(n-1)^{2}\left(1+\frac{n x}{K}\right)^{2}-\left(1-\delta q_{R}\right)^{2}\right] .
\end{aligned}
$$

\subsection{Proof of Proposition 4}

When $g_{i}$ is already negotiated, $i$ invests until

$$
\begin{aligned}
k & =\beta^{\prime}\left(g_{i}+R_{i}-\bar{y}_{i}\right) d+z D \Rightarrow \\
\widetilde{y}_{i}-\bar{y} & =\beta^{\prime-1}\left(\frac{k-z D}{d}\right), R_{i}=\beta^{\prime-1}\left(\frac{k-z D}{d}\right)+\bar{y}_{i}-g_{i}, \\
d r_{i} & =\beta^{\prime-1}\left(\frac{k-z D}{d}\right)+\bar{y}_{i}-g_{i}-q_{R} R_{i,-}-\sum_{j \neq i} e r_{j} .
\end{aligned}
$$

Anticipating this, the utility before investing is:

$$
U_{i}=\beta\left(\beta^{\prime-1}\left(\frac{k-z D}{d}\right)\right)-\mathrm{E} C(G)-k r_{i}+\sum_{j \neq i} x r_{j}+\delta U(G, R) .
$$

If the negotiations fail, the default outcome is the noncooperative outcome, giving everyone the same utility. Since the $r_{i}$ s follow from the $g_{i}$ s in (8.17), everyone understands that negotiating the $g_{i} \mathrm{~s}$ is equivalent to negotiating the $r_{i} \mathrm{~s}$. Since all countries have identical preferences w.r.t. the $r_{i} \mathrm{~s}$ (and their default utility is the same) the $r_{i} \mathrm{~s}$ are going to be equal for every $i$. Symmetry requires that $r_{i}$, and thus $\zeta \equiv\left[g_{i}+q_{R} R_{i,-}-\bar{y}_{i}\right]$, is the same for all countries. (8.17) becomes

$$
D r_{i}=\beta^{\prime-1}\left(\frac{k-z D}{d}\right)-\zeta
$$

Efficiency requires (f.o.c. of $U_{i}$ w.r.t. $\zeta$ recognizing $g_{i}=\zeta-q_{R} R_{i,-}+\bar{y}_{i}$ and $\partial r_{i} / \partial \zeta=$ $-1 / D \forall i)$ :

$$
\begin{aligned}
-n \mathrm{E} C^{\prime}(G)+K / D+n \delta U_{G}-n D \delta U_{R}(1 / D) & =0 \Rightarrow \\
\mathrm{E}^{\prime}(G)+m+z & =K / D n .
\end{aligned}
$$


Combined with (8.17), neither $G$ nor $R$ can be functions of $R_{-}\left(R_{i}\right.$ in (8.17) and (8.18) are not functions of $R_{-}$). Thus, $U_{R_{-}}=q_{R} K / D n$, just as before, and $U_{G}$ cannot be a function of $\mathrm{R}$ (since $U_{R G}=0$ ). (8.18) then implies that $\mathrm{E} G$ is a constant and, since we must have $\zeta=\left(\mathrm{E} G-q_{G} G_{-}\right) / n+q_{R} R_{-} / n-\bar{y},(8.17)$ gives $\partial r_{i} / \partial G_{-}=\left(\partial r_{i} / \partial g_{i}\right)\left(\partial g_{i} / \partial \zeta\right)\left(\partial \zeta / \partial G_{-}\right)=$ $q_{G} / D n$. Hence, $U_{G_{-}}=-q_{G} K / D n+\delta U_{R} q_{G}=-q_{G}\left(1-\delta q_{R}\right) K / D n$, giving a unique equilibrium, (8.3) and (8.4), just as before. Substituted in (8.18):

$$
\mathrm{EC}^{\prime}(G)=\left(1-\delta q_{G}\right)\left(1-\delta q_{R}\right) K / D n .
$$

This is the same pollution level as in the first best (4.3). But investments might be suboptimally low. Combining (8.19) with (8.16),

$$
\begin{gathered}
\beta^{\prime}\left(g_{i}+R_{i}-\bar{y}_{i}\right) / n-\mathrm{EC}^{\prime}(G)-m=\frac{1}{n}\left(\frac{k}{d}-\frac{K}{D}\right)+\frac{\delta q_{R} K}{D n}\left(1-\frac{D}{d n}\right)= \\
\frac{K}{D n}\left(\frac{1+(n-1) x / K}{1-(n-1) e / D}-1+\delta q_{R}\left(\frac{(D-e n)(n-1)}{D n-e n(n-1)}\right)\right)=\frac{K}{D n}\left(\frac{x D / K+e+\delta q_{R}(D / n-e)}{D /(n-1)-e}\right) .
\end{gathered}
$$

$\operatorname{Under}(\mathrm{Q}), \beta^{\prime}=b\left(g_{i}+R_{i}-\bar{y}_{i}\right)$ and $\mathrm{E} C^{\prime}=c\left(q_{G} G_{-}+\sum_{i} g_{i}\right)$, so

$$
\begin{aligned}
\left(\beta^{\prime} / n-\mathrm{E} C^{\prime}\right)^{l t}-\left(\beta^{\prime} / n-\mathrm{E} C^{\prime}\right)^{*} & =b\left(-g_{i}^{l t}+g_{i}^{*}\right) / n-c n\left(g_{i}^{l t}-g_{i}^{*}\right) \Rightarrow \\
\mathrm{E} g_{i}^{*}-g_{i}^{l t} & =\frac{K / D}{b+c n^{2}}\left(\frac{x / K+e / D+\delta q_{R}(1 / n-e / D)}{1 /(n-1)+e / D}\right) .
\end{aligned}
$$

\subsection{Proof of Proposition 5}

At the start of $t=1$, countries negotiate emission levels for every period $t \in\{1, \ldots, T\}$. The investment level in period $T$ is (8.17) for the same reasons as given above.

Anticipating the equilibrium $R_{i, T}$ (and $R_{j, T}$ ) $i$ can invest $q_{R}$ less units in period $T$ for each invested unit in period $T-1$. Thus, in period $T-1, i$ invests until:

$$
\begin{aligned}
k & =d \beta^{\prime}\left(g_{i, T-1}+R_{i, T-1}-\bar{y}_{i}\right)+\delta q_{R} k \Rightarrow \\
R_{i, T-1} & =q_{R} R_{i, T-1}+d r_{i, T-1}+\sum_{j \neq i} e r_{j, T-1}=\bar{y}_{i}-g_{i, T-1}-\beta^{\prime-1}\left(k\left(1-\delta q_{R}\right) / d\right) .
\end{aligned}
$$

The same argument applies to every period $T-t, t \in\{1, \ldots T-1\}$, and the investment level is given by the analogous equation for each period but $T$.

In equilibrium, all countries enjoy the same $y_{i}-\bar{y}_{i}$ and default utilities. Thus, just as before, they will negotiate the $g_{i}$ s such that that they will all face the same cost of investment in equilibrium. Thus, $r_{i}=r_{j}=r$ and

$$
D r=\left(\bar{y}_{i}-g_{i}-q_{R} R_{i, t-1}\right)-\beta^{\prime-1}\left(k\left(1-\delta q_{R}\right) / d\right) .
$$

For every $t \in(1, T), R_{i, t-1}$ is given by the $g_{i}$ in the previous period:

$$
\begin{aligned}
D r & =\left(\bar{y}_{i}-g_{i}-q_{R}\left(\bar{y}_{i}-g_{i}^{t-1}-\beta^{-1}\left(k\left(1-\delta q_{R}\right) / d\right)\right)\right)-\beta^{\prime-1}\left(k\left(1-\delta q_{R}\right) / d\right) \\
& =\bar{y}_{i}\left(1-q_{R}\right)-g_{i}+q_{R} g_{i}^{t-1}-\left(1-q_{R}\right) \beta^{\prime-1}\left(k\left(1-\delta q_{R}\right) / d\right) .
\end{aligned}
$$


Since $r_{i}=r_{j}$, (8.20) implies that the equilibrium $g_{i, t}+q_{R} R_{i, t-1}-\bar{y}_{i, t}$ is the same (say $\varsigma_{t}$ ) for all $i \mathrm{~s}$ :

$$
g_{i, t}+q_{R}^{t-\tau} R_{i, \tau-1}-\bar{y}_{i}=\varsigma_{t}, t \in[1, T] .
$$

All countries have the same preferences over the $\varsigma_{t} \mathrm{~s}$. Dynamic efficiency requires that the countries are not better off after a change in the $\varsigma_{t} \mathrm{~s}$ (and thus the $g_{i, t} \mathrm{~s}$ ), given by $\left(\Delta \varsigma_{t}, \Delta \varsigma_{t+1}\right)$, such that $G$ is unchanged after two periods, i.e., $\Delta \varsigma_{t} q_{G}=-\Delta \varsigma_{t+1}, t \in$ $[1, T-1]$. From (8.21), this implies

$$
\begin{aligned}
-n \mathrm{E} C^{\prime}\left(G_{t}\right) \Delta \varsigma_{t}+\Delta g_{t} K / D+\delta\left(\Delta \varsigma_{t+1}-\Delta g_{t} q_{R}\right) K / D-\delta^{2} \Delta g_{t+1} q_{R} K / D & \leq 0 \forall \Delta \varsigma_{t} \Rightarrow \\
\left(-\mathrm{E} C^{\prime} n+K / D-\delta\left(q_{G}+q_{R}\right) K / D+\delta^{2} q_{G} d_{R} K / D\right) \Delta \varsigma_{t} & \leq 0 \forall \Delta \varsigma_{t} \Rightarrow \\
-\mathrm{E}^{\prime} n+\left(1-\delta q_{R}\right)\left(1-\delta q_{G}\right) K / n D & =0 .
\end{aligned}
$$

Using (8.20),

$$
\begin{aligned}
\beta^{\prime}-\mathrm{E}^{\prime}(G) n-n m & =\frac{k\left(1-\delta q_{R}\right)}{d}-\left(1-\delta q_{R}\right)\left(1-\delta q_{G}\right) K / D-\frac{\delta q_{G}\left(1-\delta q_{R}\right) K}{D} \\
=\frac{k\left(1-\delta q_{R}\right)}{d}-\left(1-\delta q_{R}\right) K / D & =\left(\frac{k}{d}-\frac{K}{D}\right)\left(1-\delta q_{R}\right)=\frac{K}{D}\left(\frac{x / K+e / D}{1 /(n-1)-e / D}\right)\left(1-\delta q_{R}\right) .
\end{aligned}
$$

The $g_{i, T}$ satisfies (8.19) for the same reasons as in the previous proof (and since they do not influence any $\left.R_{i, t}, t<T\right)$. It is easy to check that $U_{R}$ and $U_{G}$ are the same as before.

$\operatorname{Under}(\mathrm{Q}), \beta^{\prime}=b\left(\bar{y}_{i}-g_{i}-R_{i}\right), \mathrm{E} C^{\prime}=c\left(\mathrm{E} \widetilde{G}+\sum g_{j}\right)$, and since $\beta^{\prime}-\mathrm{E} c G n-n \delta U_{G}=$ 0 for $g_{i}^{*}(R)$, we have

$$
\begin{aligned}
b\left(\bar{y}_{i}-g_{i}-R_{i}\right)-n c\left(\widetilde{G}+\sum g_{j}\right)-n \delta U_{G} & \\
-\left[b\left(\bar{y}_{i}-g_{i}^{*}-R_{i}\right)-n c\left(\widetilde{G}+\sum g_{j}^{*}\right)-n \delta U_{G}\right] & =\left(\frac{k}{d}-\frac{K}{D}\right)\left(1-\delta q_{R}\right) \Rightarrow \\
\left(g_{i}^{*}-g_{i}^{l t}\right)\left(b+c n^{2}\right)=\left(\frac{k}{d}-\frac{K}{D}\right)\left(1-\delta q_{R}\right) & =\frac{K}{D}\left(\frac{x / K+e / D}{1 /(n-1)-e / D}\right)\left(1-\delta q_{R}\right) .
\end{aligned}
$$

\subsection{Proof of Proposition 6}

The optimal $T$ balances the cost of under-investment and the cost of not knowing future $\theta$ s. In period $T$, countries invest suboptimally not only because of $e$ and $x$, but because of the hold-up problem: one more unit of $R_{i}$ in period $T+1$ is not worth much to $i$, since the other countries will take advantage of it and pollute more. When all countries invest less, $u_{i}$ declines. The loss in period $T$, compared to the earlier periods, is under $(\mathrm{Q})$ :

$$
\begin{aligned}
H & =\beta\left(y_{i, t}-\bar{y}_{i}\right)-\beta\left(y_{i, T}-\bar{y}_{i}\right)-K\left(r_{i, t}-r_{i, T}\right)\left(1-\delta q_{R}\right) \\
& =-\frac{b}{2}\left(\frac{k\left(1-\delta q_{R}\right)}{b d}\right)^{2}+\frac{b}{2}\left(\frac{k-z D}{b d}\right)^{2}-\frac{K}{D}\left(-\frac{k\left(1-\delta q_{R}\right)}{b d}+\frac{k-z D}{b d}\right)\left(1-\delta q_{R}\right) \\
& =\frac{\delta q_{R} K^{2}}{b D^{2}}\left(\frac{k}{K}-\frac{1}{n}\right)\left[\left(\frac{k / K-d / D}{d^{2} / D^{2}}\right)\left(1-\frac{\delta q_{R}}{2}\right)+\frac{\delta q_{R}(d / D-1 / n)}{2 d^{2} / D^{2}}\right] .
\end{aligned}
$$


Note that $H$ increases in $e$ (for given $D$ ), $x$ (for given $K$ ) and $n$ but decreases in $b$.

Another cost of the long-term agreement is associated with $\theta$. Although $\mathrm{E}^{\prime}$ and thus $\mathrm{E} G_{t}$ is the same for all periods,

$$
\begin{aligned}
\mathrm{E} \frac{c}{2}\left(G_{t}\right)^{2} & =\mathrm{E} \frac{c}{2}\left(\mathrm{E} G_{t}+\sum_{t^{\prime}=1}^{t} \theta_{t^{\prime}} q_{G}^{t-t^{\prime}}\right)^{2}=\frac{c}{2}\left(\mathrm{E} G_{t}\right)^{2}+\mathrm{E} \frac{c}{2}\left(\sum_{t^{\prime}=1}^{t} \theta_{t^{\prime}} q_{G}^{t-t^{\prime}}\right)^{2} \\
& =\frac{c}{2}\left(\mathrm{E} G_{t}\right)^{2}+\frac{c}{2} \sigma^{2} \sum_{t^{\prime}=1}^{t} q_{G}^{2\left(t-t^{\prime}\right)}=\frac{c}{2}\left(\mathrm{E} G_{t}^{2}\right)+\frac{c}{2} \sigma^{2}\left(\frac{1-q_{G}^{2 t}}{1-q_{G}^{2}}\right) .
\end{aligned}
$$

For the $T$ periods, the total present discounted value of this loss is $L$, given by:

$$
\begin{aligned}
L(T) & =\sum_{t=1}^{T} \frac{c}{2} \sigma^{2} \delta^{t-1}\left(\frac{1-q_{G}^{2 t}}{1-q_{G}^{2}}\right)=\frac{c \sigma^{2}}{2\left(1-q_{G}^{2}\right)} \sum_{t=1}^{T} \delta^{t-1}\left(1-q_{G}^{2 t}\right) \\
& =\frac{c \sigma^{2}}{2\left(1-q_{G}^{2}\right)}\left[\frac{1-\delta^{T}}{1-\delta}-q_{G}^{2}\left(\frac{1-\delta^{T} q_{G}^{2 T}}{1-\delta q_{G}^{2}}\right)\right] \Rightarrow \\
L^{\prime}(T) & =\frac{c \sigma^{2}\left(-\delta^{T} \ln \delta\right)}{2\left(1-q_{G}^{2}\right)}\left[\frac{1}{1-\delta}-\frac{q_{G}^{2 T+2}\left(1+\ln \left(q_{G}^{2}\right) / \ln \delta\right)}{1-\delta q_{G}^{2}}\right] .
\end{aligned}
$$

If all future agreements last $\widehat{T}$ periods, the optimal $T$ for this agreement is given by

$$
\begin{aligned}
& \min _{T} L(T)+\left(\delta^{T-1} H+\delta^{T} L(\widehat{T})\right)\left(\sum_{\tau=0}^{\infty} \delta^{\tau \widehat{T}^{\prime}}\right) \Rightarrow \\
& 0=L^{\prime}(T)+\delta^{T} \ln \delta(H / \delta+L(\widehat{T}))=L^{\prime}(T)+\delta^{T} \ln \delta(H / \delta+L(\widehat{T})) \\
& =-\delta^{T} \ln \delta\left[\frac{c \sigma^{2}}{2\left(1-q_{G}^{2}\right)}\left(\frac{1}{1-\delta}-\frac{q_{G}^{2 T+2}\left(1+\ln \left(q_{G}^{2}\right) / \ln \delta\right)}{1-\delta q_{G}^{2}}\right)-\frac{H / \delta+L(\widehat{T})}{1-\delta^{\widehat{T}^{\prime}}}\right] 8
\end{aligned}
$$

assuming some $T$ satisfies (8.23). Since $\left(-\delta^{T} \ln \delta\right)>0$ and the bracket-parenthesis increases in $T$, the loss decreases in $T$ for small $T$ but increases for large $T$, and there is a unique $T$ minimizing the loss (even if the loss function is not necessarily globally concave). Since the history $\left(G_{-}\right.$and $\left.R_{-}\right)$does not enter (8.23), $T$ satisfying (8.23) equals $\widehat{T}$, assuming also $\widehat{T}$ is optimal. Substituting $\widehat{T}=T$ and (8.22) in (8.23) gives:

$$
H / \delta=\frac{c \sigma^{2} q_{G}^{2}}{2\left(1-q_{G}^{2}\right)\left(1-\delta q_{G}^{2}\right)}\left(\frac{1-\delta^{T} q_{G}^{2 T}}{1-\delta^{T}}-q_{G}^{2 T}\left(1+\frac{\ln \left(q_{G}^{2}\right)}{\ln \delta}\right)\right),
$$

increasing in $T . T=\infty$ is optimal if the left-hand side of (8.24) is larger than the right-hand side even when $T \rightarrow \infty$ :

$$
\frac{c \sigma^{2} q_{G}^{2}}{2\left(1-q_{G}^{2}\right)\left(1-\delta q_{G}^{2}\right)}<H / \delta
$$

If $e$ (for given $D$ ), $x$ (for given $K$ ) and $n$ are large, but $b$ small, $H$ is large and (8.25) is more likely to hold and if it does not, the $T$ satisfying (8.24) is larger. If $c$ or $\sigma^{2}$ are large, (8.25) is less likely to hold and if it does not, (8.24) requires $T$ to decrease. 


\subsection{Proof of Proposition 7}

In the default outcome, a country's (interrim) utility is:

$$
W_{i}^{d e}=\beta\left(g_{i}^{d e}+R_{i}-\bar{y}_{i}\right)-C\left(\widetilde{G}+\sum g_{j}^{d e}\right)+\delta U .
$$

Since $i$ gets $1 / n$ of the renegotiation-surplus, in addition, $i$ 's utility is:

$$
W_{i}^{d e}+\frac{1}{n} \sum_{j}\left(W_{j}^{r e}-W_{j}^{d e}\right)-k r_{i}+x \sum_{j \neq i} r_{j},
$$

where $W_{i}^{r e}$ is the utilities after renegotiation. Maximizing the expectation of this expression w.r.t. $r_{i}$ gives the f.o.c.

$$
\begin{aligned}
k= & d \beta^{\prime}\left(g_{i}^{d e}+R_{i}-\bar{y}_{i}\right)(1-1 / n)+D z(1-1 / n) \\
& +\mathrm{E} \frac{D}{n} \partial\left(\sum W_{i}^{r e}\right) / \partial R-\sum_{j \neq i} \frac{1}{n}\left(e \beta^{\prime}\left(g_{j}^{d e}+R_{j}-\bar{y}_{j}\right)+D z\right) .
\end{aligned}
$$

Requiring first-best investments, $\mathrm{E} D\left(\partial\left(\sum W_{i}^{r e}\right) / \partial R\right)=K$, and since $\beta^{\prime}\left(g_{i}^{d e}+R_{i}-\bar{y}_{i}\right)$ must be the same for all $i$ s,

$$
k=\beta^{\prime}\left(g_{i}^{d e}+R_{i}^{*}-\bar{y}_{i}\right)(d-D / n)+K / n \Rightarrow \beta^{\prime}\left(g_{i}^{d e}+R_{i}^{*}-\bar{y}_{i}\right)=\frac{k n-K}{d n-D} .
$$

Combined with the optimum, (4.2),

$$
\begin{aligned}
\beta^{\prime}\left(g_{i}^{d e}+R_{i}^{*}-\bar{y}_{i}\right)-\mathrm{E} \beta^{\prime}\left(g_{i}^{*}+R_{i}^{*}-\bar{y}_{i}\right) & =\frac{k n-K}{d n-D}-\frac{K}{D}\left(1-\delta q_{R}\right) \\
& =\frac{K}{D}\left(\frac{x / K+e / D}{1 / n-e / D}+\delta q_{R}\right) .
\end{aligned}
$$

Since $y_{i}^{d e}-\bar{y}_{i}$ is the same for every $i$ in equilibrium, the bargaining game (when renegotiating the $g_{i}^{d e} \mathrm{~s}$ ) is symmetric and the renegotiated $g_{i}^{r e} \mathrm{~s}$ become efficient (just as under short-term agreements). Since the first best is implemented, $U_{R}$ and $U_{G}$ are as before. Under (Q), $\beta^{\prime}\left(g_{i}^{d e}+R_{i}-\bar{y}_{i}\right)-\mathrm{E} \beta^{\prime}\left(g_{i}^{*}+R_{i}-\bar{y}_{i}\right)=b\left(\mathrm{E} g_{i}^{*}-g_{i}^{l t}\right)$, so

$$
\mathrm{E} g_{i}^{*}-g_{i}^{d e}=\frac{K}{b D}\left(\frac{x / K+e / D}{1 / n-e / D}+\delta q_{R}\right) .
$$

Intuitively, the reason for achieving the first best is not that $i$ receives $1 / n$ of the joint surplus. To see this, suppose $i$ were recognized to make a take-it-or-leave-it offer (with transfers) with probability $p_{i}$. The expected utility of $i$ could be written, replacing (8.26):

$$
W_{i}^{d e}+p_{i} \sum_{j}\left(W_{j}^{r e}-W_{j}^{d e}\right)-k r_{i}+x \sum_{j \neq i} r_{j} .
$$

If $p_{i}=1$, this becomes

$$
\sum_{j} W_{j}^{r e}-\sum_{j \neq i} W_{j}^{d e}-k r_{i}+x \sum_{j \neq i} r_{j}
$$


and maximizing this w.r.t. $r_{i}$ is not identical to maximizing $\sum_{j} W_{j}^{r e}$, which would have given the first best. In fact, $p_{i}=1$ leads to underinvestment from $i$ since a larger $r_{i}$ improves the other countries' threat point. On the other hand, $p_{i}=0$ could motivate $i$ to invest optimally, since the f.o.c. for the investment would be:

$$
k=d \beta^{\prime}\left(g_{i}^{d e}+R_{i}-\bar{y}_{i}\right)+D z,
$$

and equilibrium investments can be arbitrarily large if just $g_{i}^{d e}$ is sufficiently small. Thus, countries may invest a lot with this renegotiation design not because they share the total surplus but because their starting point, or threat point, $W_{i}^{d e}$, is very sensitive to $r_{i}$ when $g_{i}^{d e}$ is very small.

The intuition can be strengthened by considering an example with $n \rightarrow \infty$ and, for simplicity, $x=\delta=0 \Rightarrow z=0$. If $n \rightarrow \infty$, one can let the externality be positive but finite if this is equal to some constant $E \equiv D-d$. By definition, $D-d=e(n-1)$, so this requires that the externality per country, $e=E /(n-1)$ goes to zero, but the total externality is still positive. In the limit, $i$ is simply maximizing $W_{i}^{\text {de }}$ and the first-order condition w.r.t. $r_{i},(8.27)$, becomes:

$$
k=d \beta^{\prime}\left(g_{i}^{d e}+R_{i}-\bar{y}_{i}\right) .
$$

Nevertheless, the first-best is implemented by (8.29), which becomes:

$$
\beta^{\prime}\left(g_{i}^{d e}+R_{i}^{*}-\bar{y}_{i}\right)-\mathrm{E} \beta^{\prime}\left(g_{i}^{*}+R_{i}^{*}-\bar{y}_{i}\right)=\frac{K}{D}\left(\frac{E}{D-E}\right) .
$$

Intuition: In this case, each country internalizes the externality $E$ simply by maximizing $W_{i}^{d e}$ because of the large marginal utility of a better technology in the default outcome, $\partial W_{i}^{d e} / \partial r_{i}>\partial W_{i}^{r e} / \partial r_{i}$. Countries are here investing as if they end up with the default outcome, even if they receive a larger quota in equilibrium.

An alternative intuition based on transfers can be stated as follows. In equilibrium, with the Nash Bargaining Solution, I can calculate the transfer to be $t_{i}$ to country $i$, where:

$$
t_{i}=\left(W_{i}^{d e}-\frac{1}{n-1} \sum_{j \neq i} W_{j}^{d e}\right) \frac{n-1}{n} .
$$

Thus, if $r_{i}$ changes marginally in a symmetric equilibrium, the transfer changes according to:

$$
\frac{\partial t_{i}}{\partial r_{i}}=\left(\frac{n-1}{n}\right)(d-e) \beta_{d e}^{\prime},
$$

where $\beta_{d e}^{\prime} \equiv \beta^{\prime}\left(g_{j}^{d e}+R_{j}^{*}-\bar{y}_{j}\right) \forall j$ in the symmetric equilibrium. In general, the transfer is not equal to the externality on the other countries. But to motivate first-best investments, these transfers must equal the externality, and this can always be achieved (if $d>e$ ) since $\beta_{d e}^{\prime}$ is a function of $g_{i}^{d e}$.

\subsection{Proof of Proposition 8}

Take period 1, and assume the countries renegotiate the $g_{i, 1}$ s only (a similar logic holds if they simultaneously renegotiate future emission levels). If $T>1, R_{i, t}$ for $t=2$ is 
given by $g_{i, 2}$, nothwitstanding $R_{i}^{1}$ and whether the renegotiation over $g_{i, 1}$ fails. Thus, the equilibrium first-order condition w.r.t. $r_{i}^{1}$ is:

$$
\begin{aligned}
k= & {\left[d \beta^{\prime}\left(g_{i, 1}^{d e}+R_{i, 1}-\bar{y}_{i}\right)+\delta q_{R} k\right](1-1 / n) } \\
& +\mathrm{E} \frac{D}{n} \partial\left(\sum W_{i}^{r e}\right) / \partial R-\frac{1}{n} \sum_{j \neq i} e \beta^{\prime}\left(g_{j, 1}^{d e}+R_{j, 1}-\bar{y}_{j}\right)
\end{aligned}
$$

Requiring first-best investments, $\mathrm{E} D\left(\partial\left(\sum W_{i}^{r e}\right) / \partial R\right)=K$, and since $\beta^{\prime}\left(g_{i, 1}^{d e}+R_{i, 1}-\bar{y}_{i}\right)$ must be the same for all $i$,

$$
\begin{aligned}
k\left[1-\delta q_{R}(1-1 / n)\right] & =(d-e)\left[\beta^{\prime}\left(g_{i, 1}^{d e}+R_{i}^{*}-\bar{y}_{i}\right)\right](1-1 / n)+K / n \Rightarrow \\
\beta^{\prime}\left(g_{i, 1}^{d e}+R_{i}^{*}-\bar{y}_{i}\right) & =\frac{k\left[n-\delta q_{R}(n-1)\right]-K}{d n-D} .
\end{aligned}
$$

Comparing (8.30) and (8.28) reveals that $g_{i}^{d e}$ is larger in the present case. Under (Q):

$$
\mathrm{E} g_{i}^{*}-g_{i}^{d e}=\frac{K}{D b}\left[\left(1-\delta q_{R}\right)\left(\frac{x / K+e / D}{1 / n-e / D}\right)+\frac{\delta q_{R} x / K n}{1 / n-e / D}\right]
$$

Similar argument holds for $t>1$, but since $R^{*}$ depends on the latest realization of $\theta, g_{i, t}^{d e}$ must be renegotiated after $\theta$ is realized in period $t-1$.

\subsection{Proofs of Proposition 9-10}

Under short-term agreements (as well as under no agreement), if interrim utility is $W(\widetilde{G}, R)$, investments are given by $\mathrm{E} W_{R}=k / D$ while they should optimally be $\mathrm{E} W_{R}=$ $K / D n$, requiring $K+x(n-1)=K / n \Rightarrow-x=K / n$. Under long-term agreements, the optimal $R_{i}$ is given by $\beta^{\prime}\left(g_{i}+R_{i}-\bar{y}_{i}\right) D+n z D=K$, which is the same as the equilib$\operatorname{rium} \beta^{\prime} d+z D=k$ if $-x=K\left(\delta q_{R}+e n\left(1-\delta q_{R}\right) / D\right) / n$. For an agreement lasting $T>1$ periods, $R_{i, t}, t<T$, should be $D \beta^{\prime}\left(g_{i, t}+R_{i}-\bar{y}_{i}\right)+\delta q_{R} K=K$, which is the same as the equilibrium $R_{i, t}$ if $K\left(1-\delta q_{R}\right) / D=k\left(1-\delta q_{R}\right) / d \Rightarrow-x=e K / D$. Proposition 10 follows since $x>0$ is allowed in the proofs above.

\subsection{Proofs of Propositions 11-12}

The proof of Proposition 11 is equivalent to the text following it, and thus omitted. Proposition 12 follows since heterogeneity is allowed in the proofs above. 


\section{References}

Aghion, Philippe; Dewatripont, Mathias and Rey, Patrick (1994): "Renegotiation Design with Unverifiable Information," Econometrica 62: 257-82.

Aldy, Joseph; Barrett, Scott and Stavins, Robert (2003): "Thirteen Plus One: A Comparison of Global Climate Policy Architectures," Climate Policy 3 (4): 373-97.

Aldy, Joseph and Stavins, Robert (Ed.) (2007): Architectures for Agreement: Addressing Global Climate Change in the Post-Kyoto World. Cambridge U. Press.

Barrett, Scott (2005): "The Theory of International Environmental Agreements," Handbook of Environmental Economics 3, edited by K.-G. Mäler and J.R. Vincent.

Barrett, Scott and Stavins, Robert (2003): "Increasing Participation and Compliance in International Climate Change Agreements," International Environmental Agreements: Politics, Law and Economics 3: 349-376.

Başar, Tamer and Olsder, Geert Jan (1999): Dynamic Noncooperative Game Theory. Siam, Philadelphia.

Battaglini, Marco, and Coate, Stephen (2007): "Inefficiency in Legislative Policymaking: A Dynamic Analysis," American Economic Review 97 (1): 118-49.

Beccherle, Julien and Tirole, Jean (2010): "Regional Initiatives and the Cost of Delaying Binding Climate Change Agreements," mimeo, Toulouse School of Economics.

Buchholz, Wolfgang and Konrad, Kai (1994): "Global Environmental Problems and the Strategic Choice of Technology," Journal of Economics 60 (3): 299-321.

Che, Yeon-Koo and Hausch, Donald B. (1999): "Cooperative Investments and the Value of Contracting," American Economic Review 89 (1): 125-46.

Che, Yeon-Koo and Sakovics, Jozsef (2004): "A Dynamic Theory of Holdup," Econometrica 72 (4): 1063-1103.

Chung, Tai-Yeong (1991): "Incomplete Contracts, Specific Investment, and Risk Sharing," Review of Economic Studies 58 (5): 1031-42.

Coe, David T. and Helpman, Elhanan (1995): "International R\&D spillovers," European Economic Review 39 (5): 859-87.

d'Aspremont, Claude and Jacquemin, Alexis (1988): "Cooperative and Noncooperative R\&D in Duopoly with Spillovers," American Economic Review 78 (5): 1133-37.

Dockner, Engelbert J.; Jørgensen, Steffen; Van Long, Ngo and Sorger, Gerhard (2000): Differential Games in Economics and Management Science, Cambridge U. Press.

Dockner, Engelbert J. and Long, Ngo Van (1993): "International Pollution Control: Cooperative versus Noncooperative Strategies," Journal of Environmental Economics and Management 24: 13-29.

Dockner, Engelbert J. and Sorger, Gerhard (1996): "Existence and Properties of Equilibria for a Dynamic Game on Productive Assets," Journal of Economic Theory 71: 209-27.

Doraszelski, Ulrich and Pakes, Ariel (2007): "A Framework for Applied Dynamic Analysis in IO," Handbook of Industrial Organization 3, North-Holland, Amsterdam: 18871966.

Dutta, Prajit K. and Radner, Roy (2004): "Self-enforcing climate-change treaties," Proc. Nat. Acad. Sci. U.S., 101, 4746-51.

Dutta, Prajit K. and Radner, Roy (2009): "A Strategic Analysis of Global Warming: 
Theory and Some Numbers," Journal of Economic Behavior \& Organization 71 (2): 187-209.

Edlin, Aaron S. and Reichelstein, Stefan (1996): "Hold-ups, Standard Breach Remedies, and Optimal Investment," American Economic Review 86 (3): 478-501.

Ellman, Matthew (2006): "The Optimal Length of Contracts with Application to Outsourcing," mimeo, UPF.

Engwerda, Jacob C. (2005): LQ Dynamic Optimization and Differential Games. Wiley.

Evans, Robert (2008): "Simple Efficient Contracts in Complex Environments," Econometrica 76 (3): 459-91.

Fershtman, Chaim and Nitzan, Shmuel (1991): "Dynamic voluntary provision of public goods," European Economic Review 35 (5): 1057-67.

Fershtman, Chaim and Pakes, Ariel. (2000): "A Dynamic Oligopoly with Collusion and Price Wars," RAND Journal of Economics 31 (2): 207-36.

Fudenberg, Drew and Tirole, Jean (1990): "Moral Hazard and Renegotiation in Agency Contracts," Econometrica 58 (6): 1279-1319.

Fudenberg, Drew and Tirole, Jean (1991): Game Theory. MIT Press.

Gatsios, Konstantine and Karp, Larry (1992): "How Anti-Merger Laws can Reduce Investment, Help Producers, and Harm Consumers," Journal of Industrial Economics 40 (3): 339-48.

Golombek, Rolf and Hoel, Michael (2005): "Climate Policy under Technology Spillovers," Environmental and Resource Economics 31 (2): 201-27.

Guriev, Sergei and Kvasov, Dmitriy (2005): "Contracting on Time," American Economic Review 95 (5): 1269-1385.

Harris, Milton and Holmstrom, Bengt (1987): "On The Duration of Agreements," International Economic Review 28 (2): 389-406.

Hart, Oliver D. and John Moore (1988). "Incomplete Contracts and Renegotiation," Econometrica 56: 755-85.

Hoel, Michael (1993): "Intertemporal properties of an international carbon tax," Resource and Energy Economics 15 (1): 51-70.

Hoel, Michael and de Zeeuw, Aart (2009): "Can a Focus on Breakthrough Technologies Improve the Performance of International Environmental Agreements?" NBER Working Paper 15043.

Houba, Harold; Sneek, Koos and Vardy, Felix (2000): "Can negotiations prevent fish wars?" Journal of Economic Dynamics and Control 24 (8): 1265-80.

Jaffe, Adam B.; Newell, Richard G. and Stavins, Robert N. (2003): "Technological Change and the Environment," Handbook of Environmental Economics 1 (edited by K.-G. Mäler and J.R. Vincent), Elsevier.

Karp, Larry S. and Zhao, Jinhua (2009): "A Proposal for the Design of the Successor to the Kyoto Protocol," mimeo, UC Berkeley.

Kolstad, Charles D. and Toman, Michael (2005): "The Economics of Climate Policy," Handbook of Environmental Economics 3: 1562-93.

Levhari, David and Mirman, Leonard J. (1980): "The Great Fish War: An Example Using a Dynamic Cournot-Nash Solution," Bell Journal of Economics 11 (1): 322-34.

Marx, Leslie M. and Matthews, Steven A. (2000): "Dynamic Voluntary Contribution to a Public Project," Review of Economic Studies 67: 327-58. 
Maskin, Eric and Tirole, Jean (2001): "Markov Perfect Equilibrium: I. Observable Actions," Journal of Economic Theory 100 (2): 191-219.

Muuls, Mirabelle (2009): "The effect of investment on bargaining positions. Overinvestment in the case of international agreements on climate change," mimeo, Imperial College London.

Newell, Richard G.; Jaffe, Adam B. and Stavins, Robert N. (2006): "The Effects of Economic and Policy Incentives on Carbon Mitigation Technologies," Energy Economics 28: 563-78.

Ploeg, Frederick van der and de Zeeuw, Aart (1991): "A differential game of international pollution control," Systems \& Control Letters 17 (6): 409-14.

Ploeg, Frederick van der and de Zeeuw, Art (1992): "International aspects of pollution control," Environmental and Resource Economics 2 (2): 117-39.

Reynolds, Stanley S. (1987): "Capacity Investment, Preemption and Commitment in an Infinite Horizon Model," International Economic Review 28 (1): 69-88.

Rubio, Santiago J. and Ulph, Alistar (2007): "An infinite-horizon model of dynamic membership of international environmental agreements," Journal of Environmental Economics and Management 54 (3): 296-310.

Segal, Ilya and Whinston, Michael D. (2002): "The Mirrless Approach to Mechanism Design With Renegotiation," Econometrica 70 (1): 1-45.

Sorger, Gerhard (1998): "Markov-Perfect Nash Equilibria in a Class of Resource Games," Economic Theory 11: 79-100.

Sorger, Gerhard (2006): "Recursive Nash Bargaining Over a Productive Asset," Journal of Economic Dynamics and Control 30 (12): 2637-59.

Tsutsui, Shunichi and Mino, Kazuo (1990): "Nonlinear Strategies in Dynamic Duopolistic Competition with Sticky Prices," Journal of Economic Theory 52: 136-61.

Wirl, Franz (1996): "Dynamic voluntary provision of public goods: Extension to nonlinear strategies," European Journal of Political Economy 12 (3): 555-60.

Yanase, Akihiko (2006): "Dynamic Voluntary Provision of Public Goods and Optimal Steady-State Subsidies," Journal of Public Economic Theory 8 (1): 171-9. 


\section{CESifo Working Paper Series}

for full list see www.cesifo-group.org/wp

(address: Poschingerstr. 5, 81679 Munich, Germany, office@cesifo.de)

2901 Donatella Gatti, Christophe Rault and Anne-Gaël Vaubourg, Unemployment and Finance: How do Financial and Labour Market Factors Interact?, December 2009

2902 Arno Riedl, Behavioral and Experimental Economics Can Inform Public Policy: Some Thoughts, December 2009

2903 Wilhelm K. Kohler and Marcel Smolka, Global Sourcing Decisions and Firm Productivity: Evidence from Spain, December 2009

2904 Marcel Gérard and Fernando M. M. Ruiz, Corporate Taxation and the Impact of Governance, Political and Economic Factors, December 2009

2905 Mikael Priks, The Effect of Surveillance Cameras on Crime: Evidence from the Stockholm Subway, December 2009

2906 Xavier Vives, Asset Auctions, Information, and Liquidity, January 2010

2907 Edwin van der Werf, Unilateral Climate Policy, Asymmetric Backstop Adoption, and Carbon Leakage in a Two-Region Hotelling Model, January 2010

2908 Margarita Katsimi and Vassilis Sarantides, Do Elections Affect the Composition of Fiscal Policy?, January 2010

2909 Rolf Golombek, Mads Greaker and Michael Hoel, Climate Policy without Commitment, January 2010

2910 Sascha O. Becker and Ludger Woessmann, The Effect of Protestantism on Education before the Industrialization: Evidence from 1816 Prussia, January 2010

2911 Michael Berlemann, Marco Oestmann and Marcel Thum, Demographic Change and Bank Profitability. Empirical Evidence from German Savings Banks, January 2010

2912 Øystein Foros, Hans Jarle Kind and Greg Shaffer, Mergers and Partial Ownership, January 2010

2913 Sean Holly, M. Hashem Pesaran and Takashi Yamagata, Spatial and Temporal Diffusion of House Prices in the UK, January 2010

2914 Christian Keuschnigg and Evelyn Ribi, Profit Taxation and Finance Constraints, January 2010

2915 Hendrik Vrijburg and Ruud A. de Mooij, Enhanced Cooperation in an Asymmetric Model of Tax Competition, January 2010 
2916 Volker Meier and Martin Werding, Ageing and the Welfare State: Securing Sustainability, January 2010

2917 Thushyanthan Baskaran and Zohal Hessami, Globalization, Redistribution, and the Composition of Public Education Expenditures, January 2010

2918 Angel de la Fuente, Testing, not Modelling, the Impact of Cohesion Support: A Theoretical Framework and some Preliminary Results for the Spanish Regions, January 2010

2919 Bruno S. Frey and Paolo Pamini, World Heritage: Where Are We? An Empirical Analysis, January 2010

2920 Susanne Ek and Bertil Holmlund, Family Job Search, Wage Bargaining, and Optimal Unemployment Insurance, January 2010

2921 Mariagiovanna Baccara, Allan Collard-Wexler, Leonardo Felli and Leeat Yariv, Gender and Racial Biases: Evidence from Child Adoption, January 2010

2922 Kurt R. Brekke, Roberto Cellini, Luigi Siciliani and Odd Rune Straume, Competition and Quality in Regulated Markets with Sluggish Demand, January 2010

2923 Stefan Bauernschuster, Oliver Falck and Niels Große, Can Competition Spoil Reciprocity? - A Laboratory Experiment, January 2010

2924 Jerome L. Stein, A Critique of the Literature on the US Financial Debt Crisis, January 2010

2925 Erkki Koskela and Jan König, Profit Sharing, Wage Formation and Flexible Outsourcing under Labor Market Imperfection, January 2010

2926 Gabriella Legrenzi and Costas Milas, Spend-and-Tax Adjustments and the Sustainability of the Government's Intertemporal Budget Constraint, January 2010

2927 Piero Gottardi, Jean Marc Tallon and Paolo Ghirardato, Flexible Contracts, January 2010

2928 Gebhard Kirchgässner and Jürgen Wolters, The Role of Monetary Aggregates in the Policy Analysis of the Swiss National Bank, January 2010

2929 J. Trent Alexander, Michael Davern and Betsey Stevenson, Inaccurate Age and Sex Data in the Census PUMS Files: Evidence and Implications, January 2010

2930 Stefan Krasa and Mattias K. Polborn, Competition between Specialized Candidates, January 2010

2931 Yin-Wong Cheung and Xingwang Qian, Capital Flight: China’s Experience, January 2010 
2932 Thomas Hemmelgarn and Gaetan Nicodeme, The 2008 Financial Crisis and Taxation Policy, January 2010

2933 Marco Faravelli, Oliver Kirchkamp and Helmut Rainer, Social Welfare versus Inequality Concerns in an Incomplete Contract Experiment, January 2010

2934 Mohamed El Hedi Arouri and Christophe Rault, Oil Prices and Stock Markets: What Drives what in the Gulf Corporation Council Countries?, January 2010

2935 Wolfgang Lechthaler, Christian Merkl and Dennis J. Snower, Monetary Persistence and the Labor Market: A New Perspective, January 2010

2936 Klaus Abberger and Wolfgang Nierhaus, Markov-Switching and the Ifo Business Climate: The Ifo Business Cycle Traffic Lights, January 2010

2937 Mark Armstrong and Steffen Huck, Behavioral Economics as Applied to Firms: A Primer, February 2010

2938 Guglielmo Maria Caporale and Alessandro Girardi, Price Formation on the EuroMTS Platform, February 2010

2939 Hans Gersbach, Democratic Provision of Divisible Public Goods, February 2010

2940 Adam Isen and Betsey Stevenson, Women's Education and Family Behavior: Trends in Marriage, Divorce and Fertility, February 2010

2941 Peter Debaere, Holger Görg and Horst Raff, Greasing the Wheels of International Commerce: How Services Facilitate Firms’ International Sourcing, February 2010

2942 Emanuele Forlani, Competition in the Service Sector and the Performances of Manufacturing Firms: Does Liberalization Matter?, February 2010

2943 James M. Malcomson, Do Managers with Limited Liability Take More Risky Decisions? An Information Acquisition Model, February 2010

2944 Florian Englmaier and Steve Leider, Gift Exchange in the Lab - It is not (only) how much you give ..., February 2010

2945 Andrea Bassanini and Giorgio Brunello, Barriers to Entry, Deregulation and Workplace Training: A Theoretical Model with Evidence from Europe, February 2010

2946 Jan-Emmanuel De Neve, James H. Fowler and Bruno S. Frey, Genes, Economics, and Happiness, February 2010

2947 Camille Cornand and Frank Heinemann, Measuring Agents’ Reaction to Private and Public Information in Games with Strategic Complementarities, February 2010

2948 Roel Beetsma and Massimo Giuliodori, Discretionary Fiscal Policy: Review and Estimates for the EU, February 2010 
2949 Agnieszka Markiewicz, Monetary Policy, Model Uncertainty and Exchange Rate Volatility, February 2010

2950 Hans Dewachter and Leonardo Iania, An Extended Macro-Finance Model with Financial Factors, February 2010

2951 Helmuth Cremer, Philippe De Donder and Pierre Pestieau, Education and Social Mobility, February 2010

2952 Zuzana Brixiová and Balázs Égert, Modeling Institutions, Start-Ups and Productivity during Transition, February 2010

2953 Roland Strausz, The Political Economy of Regulatory Risk, February 2010

2954 Sanjay Jain, Sumon Majumdar and Sharun W. Mukand, Workers without Borders? Culture, Migration and the Political Limits to Globalization, February 2010

2955 Andreas Irmen, Steady-State Growth and the Elasticity of Substitution, February 2010

2956 Bengt-Arne Wickström, The Optimal Babel - An Economic Framework for the Analysis of Dynamic Language Rights, February 2010

2957 Stefan Bauernschuster and Helmut Rainer, From Politics to the Family: How Sex-Role Attitudes Keep on Diverging in Reunified Germany, February 2010

2958 Patricia Funk and Christina Gathmann, How do Electoral Systems Affect Fiscal Policy? Evidence from State and Local Governments, 1890 to 2005, February 2010

2959 Betsey Stevenson, Beyond the Classroom: Using Title IX to Measure the Return to High School Sports, February 2010

2960 R. Quentin Grafton, Tom Kompas and Ngo Van Long, Biofuels Subsidies and the Green Paradox, February 2010

2961 Oliver Falck, Stephan Heblich, Alfred Lameli and Jens Suedekum, Dialects, Cultural Identity, and Economic Exchange, February 2010

2962 Bård Harstad, The Dynamics of Climate Agreements, February 2010 